\title{
Adsorptive removal of nitrogen from coal-based needle coke feedstocks using activated carbon
}

\author{
Sreeja Madala \\ West Virginia University
}

Follow this and additional works at: https://researchrepository.wvu.edu/etd

\section{Recommended Citation}

Madala, Sreeja, "Adsorptive removal of nitrogen from coal-based needle coke feedstocks using activated carbon" (2009). Graduate Theses, Dissertations, and Problem Reports. 2071.

https://researchrepository.wvu.edu/etd/2071

This Thesis is protected by copyright and/or related rights. It has been brought to you by the The Research Repository @ WVU with permission from the rights-holder(s). You are free to use this Thesis in any way that is permitted by the copyright and related rights legislation that applies to your use. For other uses you must obtain permission from the rights-holder(s) directly, unless additional rights are indicated by a Creative Commons license in the record and/ or on the work itself. This Thesis has been accepted for inclusion in WVU Graduate Theses, Dissertations, and Problem Reports collection by an authorized administrator of The Research Repository @ WVU. For more information, please contact researchrepository@mail.wvu.edu. 


\title{
Adsorptive Removal of Nitrogen from Coal-Based Needle Coke Feedstocks Using Activated Carbon
}

\author{
Sreeja Madala
}

Thesis submitted to the

College of Engineering and Mineral Resources

at West Virginia University

in partial fulfillment of the requirements for the degree of

\author{
Master of Science \\ in \\ Chemical Engineering \\ John W. Zondlo, Ph.D., Chair \\ Liviu Magean, M.S. \\ Peter G. Stansberry, Ph.D.
}

Department of Chemical Engineering

West Virginia University

Morgantown, WV

2009

Keywords: Coal Tar Distillate; Activated Carbon; Nitrogen Removal;

Needle-coke feedstocks; Adsorption

Copyright 2009 Sreeja Madala 


\title{
ABSTRACT \\ Adsorptive Removal of Nitrogen from Needle Coke Feedstocks Using Coal-Derived Activated Carbon
}

\author{
Sreeja Madala
}

A low percentage of nitrogen in needle coke feedstocks is desired for the reduction of puffing during the process of graphitization of needle coke. The purpose of the present study is to investigate the removal of nitrogen species from a coal-based needle coke feedstock, when treated with both commercial activated carbon, Nuchar SA 20 and "coal-derived" activated carbon, WVUAC 900-15. Koppers coal tar distillate (CTD), which has $1.1 \% \mathrm{wt}$ starting nitrogen content, is selected as the needle coke feedstock. A series of experiments was performed to establish a standard procedure for the removal of nitrogen species. Using the established experimental procedure, experiments were conducted to determine the effect of solvent, time and amount of activated carbon on the adsorption capacity of nitrogen for both Nuchar and WVUAC 900-15 activated carbons. Also, the surface properties of both the activated carbons were modified via oxidation with nitric acid and air. The oxidized activated carbons were then tested as adsorbents for the de-nitrogenation of CTD. From the $\mathrm{pH}$ test results, it is observed that oxidation modification has improved acidic surface functional groups on activated carbons. In an experiment it is observed that $92 \%$ of the nitrogen was removed from the CTD with $9 \mathrm{~g}$ of Nuchar SA20. Unfortunately the result was not repeatable. No reasonable explanations were found for this but it is suspected that aging of the CTD which may change the nitrogen compounds in CTD and error in the sampling technique are possible reasons. Oxidized activated carbons performed $10-15 \%$ better than unoxidized activated carbon in removing nitrogen species. The coefficient of thermal expansion (CTE) of the graphite test specimen prepared with de-nitrogenated CTD is measured as $0.209 \mathrm{ppm} /{ }^{\circ} \mathrm{C}$ while $\mathrm{CTE}$ of the graphite test specimen prepared with a petroleum-based needle-coke feedstock, decant oil, is $0.250 \mathrm{ppm} /{ }^{\circ} \mathrm{C}$ 


\section{ACKNOWLEDGEMENTS}

I am especially grateful to my advisor and professor Dr. John W. Zondlo for his encouragement, guidance and his support throughout the course of my graduate program. I would like to extend my gratitude to Mr. Liviu Magean for his invaluable assistance and recommendations. I also appreciate your participation and enthusiasm to be part of my committee. My gratitude is also extended to Dr. Peter G. Stansberry for his help and support. Thank you for your commitment towards being a part of my committee.

My most sincere thanks to Mrs. Gabriela Perhinschi for her effort in analyzing my samples. Many thanks to Mr. Jim Hall for his assistance in the laboratory. I would like to express my warm gratitude and thanks to Mr. Avram Siegel who has always there for me. Special thanks to all the faculty and staff of the department of Chemical Engineering.

I am extremely thankful and greatly indebted to my parents, Mr. M.R. Subba Rao and Mrs. M. Prabhvathi, for always being with me. Thank you for all your love and constant support. 


\section{TABLE OF CONTENTS}

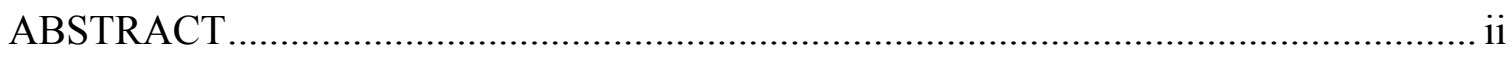

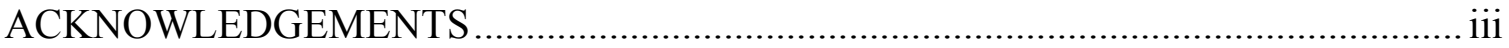

TABLE OF CONTENTS.............................................................................................. iv

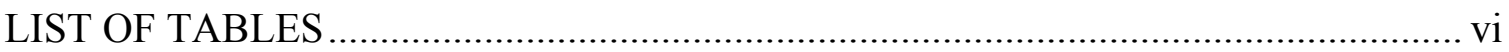

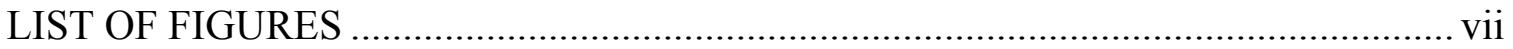

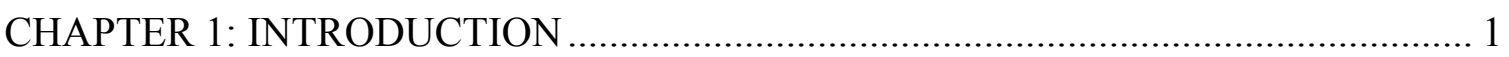

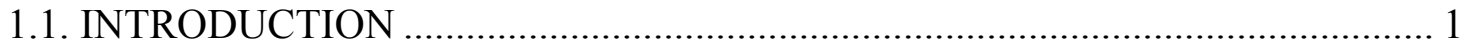

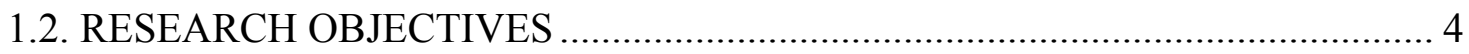

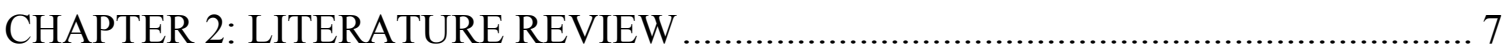

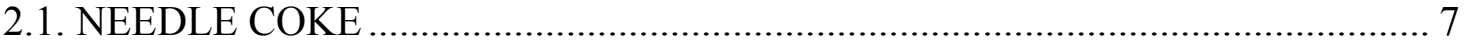

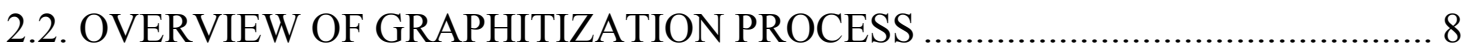

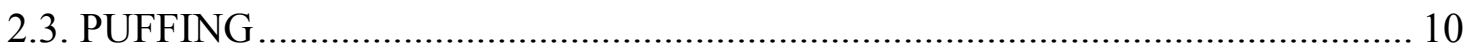

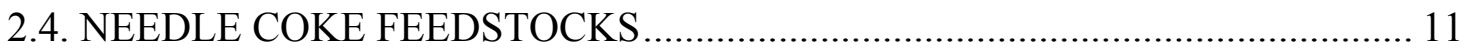

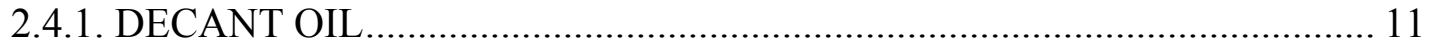

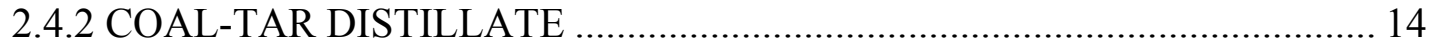

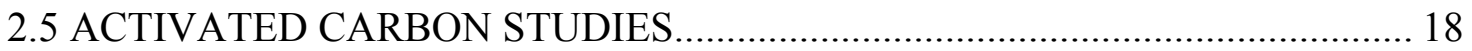

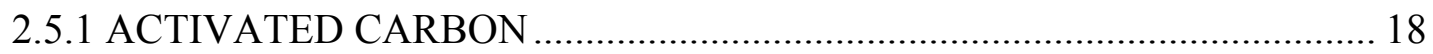

2.5.2 METHODS OF ACTIVATION …………............................................... 18

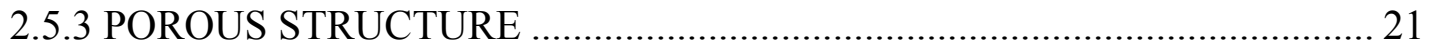

2.5.4 COMMERCIAL ACTIVATED CARBONS ................................................. 22

2.5.5 IMPORTANCE OF SURFACE FUNCTIONAL GROUPS ........................... 24

CHAPTER 3: EXPERIMENTAL .............................................................................. 26

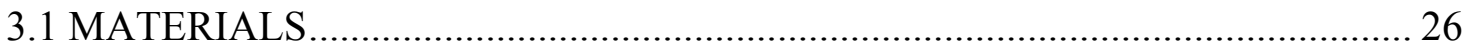

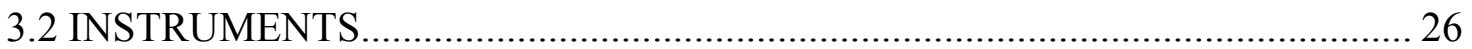

3.2.1 FLASH ELEMENTAL ANALYZER 1112 ………................................. 27

3.2.2 ACCELERATED SURFACE AREA POROSIMETRY 2020....................... 29

3.2.3 SHAKING WATER BATH ………………......................................... 31

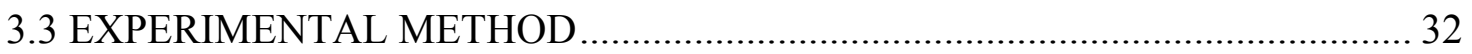

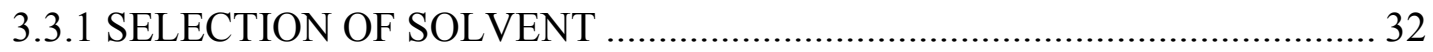

3.3.2 DETERMINATION OF SOLVENT: CTD WEIGHT RATIO ....................... 34

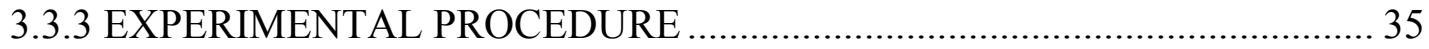

3.4 DEVELOPMENT OF SURFACE ACIDIC GROUPS ....................................... 37 


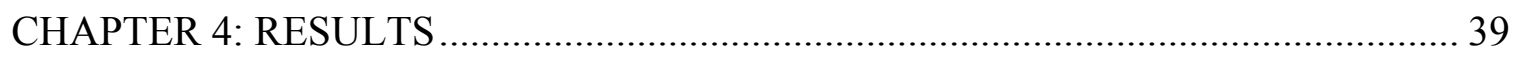

4.1 EFFECT OF SOLVENT AND AMOUNT OF NUCHAR SA $20 \ldots \ldots \ldots \ldots \ldots \ldots \ldots \ldots . . . . . . . . . . . . . . .40$

4.1.1 CARBON DISULFIDE AS SOLVENT …………….................................... 40

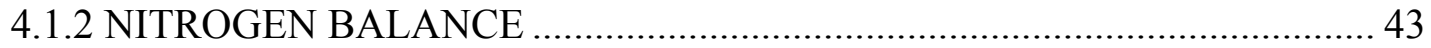

4.1.3 TESTING TETRAHYDROFURAN AS SOLVENT ...................................... 44

4.2 TWO STEP ADSORPTION PROCESS ………............................................ 45

4.3 EFFECT OF CONTACT TIME ON NITROGEN REMOVAL ………….............. 46

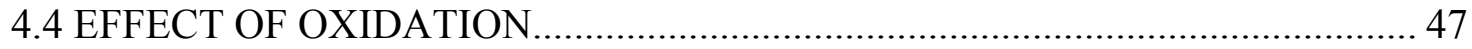

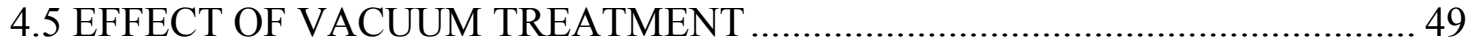

4.6 EFFECT OF WVUAC 900-15 ACTIVATED CARBON ……………................... 51

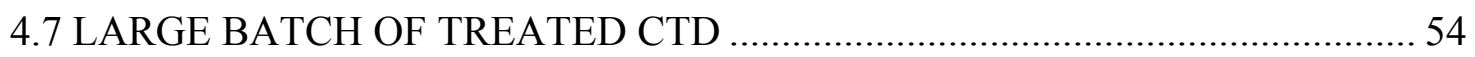

CHAPTER 5: CONCLUSIONS/RECOMMENDATIONS ............................................. 59

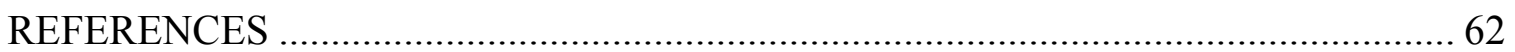




\section{LIST OF TABLES}

Table 2.1 Typical boiling point ranges of crude oil fractions.......................................... 11

Table 2.2 Elemental analysis of coal-tar and decant oil ................................................ 13

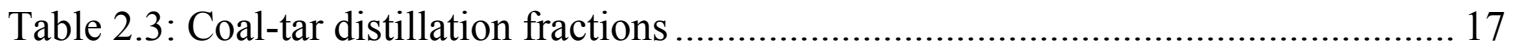

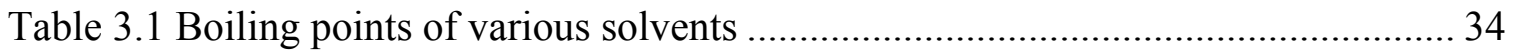

Table 3.2 Results of solubility test when $\mathrm{CS}_{2}$ is used as solvent..................................... 35

Table 3.3 Data showing weight change of the CTD solution Vs time as solvent is

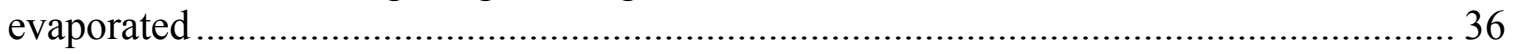

Table 4.1 Weight and nitrogen content of CTD during overnight treatment without the presence of activated carbon......................................................................................... 40

Table 4.2 Nitrogen content and yield of CTD when 4:1 $\mathrm{CS}_{2}$ : CTD solution was treated

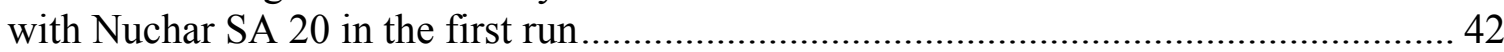

Table 4.3 Nitrogen content and yield of CTD when 4:1 $\mathrm{CS}_{2}$ : CTD solution was treated

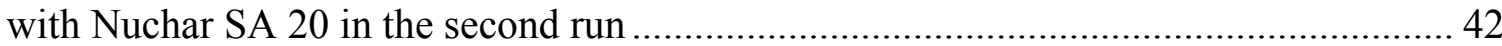

Table 4.4 Nitrogen distribution between CTD solution and Nuchar SA 20 activated

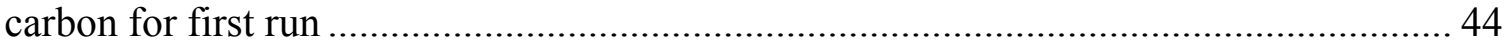

Table 4.5 Nitrogen distribution between CTD solution and Nuchar SA 20 activated

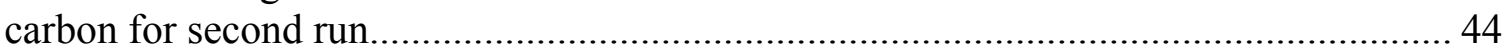

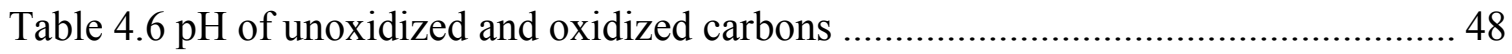

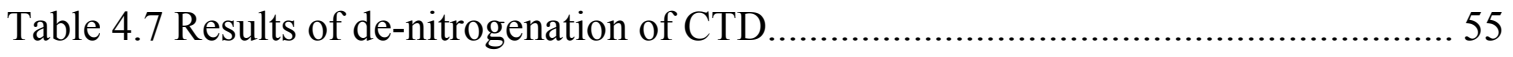

Table 4.8 Statistical results on treating CTD with air oxidized Nuchar SA20 …............. 57

Table 4.9 Product yield from batch cocking of de-nitrogenated Koppers CTD ............... 57

Table 4.10 Properties of graphite test specimens...................................................... 58 


\section{LIST OF FIGURES}

Figure 2.1 Cross-sectional view of needle coke ................................................. 7

Figure 2.2 Making of graphite electrode..................................................................... 9

Figure 2.3 Basic flow diagram of a modern petroleum refinery................................. 13

Figure 2.4 Production of Coal Tar Distillate ............................................................ 16

Figure 2.5 General flow sheet for manufacture of activated carbon............................ 20

Figure 2.6 Activated carbon structure- schematic ................................................ 22

Figure 2.7 Forms of activated carbon

A-Powdered form, B-Granular form and C-Pelletized form. ..................................... 23

Figure 3.1 Schematic diagram of the elemental analyzer set up for nitrogen analysis.... 28

Figure 3.2 Isotherm Linear Plot for Nuchar SA20 ................................................. 30

Figure 3.3 Experimental setup showing shaker bath with sample flasks ...................... 32

Figure 3.4 Solubility of CTD in toluene at 1:1, 2:1, 3:1, 4:1 and 5:1 toluene to CTD wt ratios

Figure 4.1 Plot of percent nitrogen removed Vs. amount of Nuchar activated carbon with $\mathrm{CS}_{2}$ as the Solvent at $30^{\circ} \mathrm{C}$.

Figure.4.2 Testing THF as a solvent with increasing amounts of Nuchar SA20 for 2 hrs at $30^{\circ} \mathrm{C}$.

Figure 4.3 Effect of two-step adsorption process compared to a one-step process .......... 46

Figure 4.4 Effect of contact time on \% nitrogen removal when $5 \mathrm{~g}$ of air oxidized Nuchar activated carbon is contacted with solution of $\mathrm{CS}_{2}$ and CTD at 4:1 wt ratio. 47

Figure 4.5 Effect of oxidized carbons on nitrogen removal ...................................... 49

Figure 4.6 Effect of vacuum treatment of activated carbon on nitrogen removal ........... 50

Figure 4.7 Effect of increasing amounts of WVUAC900-15 when $\mathrm{CS}_{2}$ is solvent ......... 52 
Figure 4.8 Percent nitrogen removed plotted against contact time between $5 \mathrm{~g}$ of WVUAC 900-15 and 4:1 wt ratio solution of $\mathrm{CS}_{2}$ and CTD......

Figure 4.9 Plot showing percent nitrogen removed with unoxidized, nitric acid oxidized

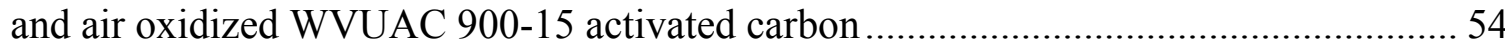




\section{CHAPTER 1: INTRODUCTION}

\subsection{INTRODUCTION}

Graphite is an allotropic form of the element carbon. The graphite crystal is constructed of layer upon layer of two-dimensional, connected, six member carbon rings. Graphitic materials are generally polycrystalline; the material consists of an agglomeration of smaller graphite crystallites into a three-dimensional mosaic. The bulk properties of the material are a function of the size of the crystallites, relative orientation of the crystallites within the mosaic, the intra-crystallite perfection (spacing between the carbon lamellae, presence of crystal lattice imperfections, etc.), and the inter-crystallite perfection (fractures, stresses, etc.). The bulk properties of the material can be altered by modifying any of the above crystallographic properties and, as a result, the bulk properties can be tailored to fit specific needs [1].

Graphite, in the purest sense, is a mineral and is found in igneous rock sites where carbonaceous material has been exposed to high temperature and high pressure. It is mined and used for some applications. But because of the large demand, it is generally manufactured from carbon-based precursors.

Synthetic graphite is used by the metallurgical industry in electric arc furnaces to melt and refine steel. This is done by passing a high-current through conductive graphite rods creating an electric arc. This electrical arc, not only melts the reprocessed steel, but mixes the contents of the pot for uniform alloy distribution. The conductive rods in arc 
furnaces are often referred to as graphite electrodes. The main constituent for the manufacture of graphite electrodes is a highly-oriented coke referred to as needle coke. Needle coke is a very special material that meets stringent industrial standards for the manufacture of graphite electrodes. The structure and properties of a graphite electrode are dependent upon the method of production, production parameters and the quality of the feedstock material i.e., needle coke. The quality of needle coke in turn depends on the purity of its feedstocks. Needle coke can be manufactured from both coal-based and petroleum-based feedstocks [2]. There is a demand of one million metric tons of needle coke worldwide per year. Among this demand, less than 15 percent of the coke needs are supplied by coal-based feedstocks.

In the United States, there is no coal-based needle coke producer at all. Two needle coke producers, Conoco-Phillips and Seadrift Coke, are using petroleum feedstock to produce coke. Coal is one of the most abundant natural resources in United States. Due to its vast supply, it could serve as a raw material that may have many advantages in the future by replacing petroleum-based fuels and carbon-product feedstocks. Coal-based carbon feedstocks such as pitch and cokes can be derived from by-product coke ovens. Unfortunately, the U.S. supply of coal tar pitch is declining due to increased imports, reduction in blast furnace steel making and environmental constraints placed on coke ovens [3]. On the other hand, the reserves of petroleum, which supply the world demand for fuel, are dwindling. One disadvantage of petroleum coke is that its availability in the United States depends upon imported crude oil sources. Also, since it is a by-product, the possibility of uncontrolled variability is ever present. Furthermore, crude oil is tending to 
increase in impurities, such as sulfur, vanadium and nickel which are detrimental to coke utilization.

Other than the availability, coal-based feedstocks have inherent advantages over petroleum cokes because of their molecular structure. In general, coal-based feedstock is more aromatic and has less side chains attached to the aromatic rings. If treated properly, the coefficient of thermal expansion (CTE) for needle coke from coal-based feedstock could be superior to that from petroleum-based feedstock. However the needle coke obtained from coal-based feedstock typically has a high puffing behavior during graphitization, due to its high nitrogen content. Thus the nitrogen compounds need to be eliminated prior to coking and graphitization.

Many studies have been attempted to reduce puffing during graphite manufacture. However, there is little technology practically used in industry. A puffing inhibitor is perhaps the simplest method. Generally iron oxide is used as a puffing inhibitor during the critical heat-treatment stage. This inhibitor is added at 1 to 2 percent to the needle coke at kneading. Iron oxide has been reported to be effective in suppressing the puffing of petroleum coke, but not effective for coal-tar-based coke. Iron oxide is believed to react with the sulfur in the coke, delaying the timing of the sulfur release. The sulfur content of the coal-tar-based coke is much less than that of petroleum coke, thus the reason for the ineffectiveness of iron oxide on the puffing of the coal-tar-based coke [4]. However nitrogen is present in coal-tar based feedstock and it too can cause puffing. 


\subsection{RESEARCH OBJECTIVES}

Recently it has been shown that activated carbon, when contacted with high-sulfur diesel fuel, could selectively remove the organic sulfur species and thereby reduce the overall sulfur content of the fuel [4]. The properties of activated carbon and the reasons for its capability to adsorb sulfur and nitrogen species from diesel fuel are discussed in detail in Chapter 2. This same technique may be applicable to the removal of nitrogen species from the coal tar distillates and hence expedite the production of coal-based needle cokes. This will be the focus of the present research.

The specific objectives for this work are:

1. Acquire coal-derived feedstock from GrafTech International for treatment with activated carbon. The feedstock will be analyzed for nitrogen content prior to and after treatment.

2. Acquire a commercial activated carbon of high surface area. And a second coalderived activated carbon will be prepared at West Virginia University from another project. Both the carbons will be evaluated for their BET surface area and average pore size using the ASAP 2020 instrument. Oxidation of the commercial activated carbon will also be performed and the resultant carbon will be evaluated and tested along with the raw commercial carbon. 
3. As the coal-derived feedstock is a highly viscous fluid at room temperature, a technique will be developed for contacting it with activated carbon. Some preliminary experiments will be conducted to establish a standard procedure for the adsorption studies. The experimental procedure includes

i. Selection of solvent to dilute the coal tar distillate

ii. Finding an appropriate ratio of solvent-to-coal tar distillate in the solution

iii. Determination of the appropriate amount of carbon to be added to the solution i.e., carbon-to-solution ratio

iv. Separation of carbon from the solution by vacuum filtration

v. Solvent recovery by evaporation to get treated feedstock without any solvent contamination for nitrogen analysis

vi. Determine the content of nitrogen in the treated pitch

4. Once the experimental procedure is established, adsorption experiments will be initiated with raw and oxidized commercial activated carbon to determine the effect of contact time between coal tar distillate-solvent mixture and the activated carbon. The effect of the amount of activated carbon added to the coal-tar solution on removal of nitrogen compounds will be assessed.

5. A large batch of feedstock treated with activated carbon will be prepared and supplied to GrafTech International for making coke in a bench-scale delayed coking unit. 
6. Finally, coal-derived activated carbon, both raw and oxidized prepared at West Virginia University from anthracite coal will be tested for its efficiency in removing nitrogen compounds. 


\section{CHAPTER 2: LITERATURE REVIEW}

\subsection{NEEDLE COKE}

Needle coke is a highly structured, superior quality carbon and has large unidirectional elliptical interconnected pores surrounded by thick fragile walls. This type of coke is more anisotropic [5]. The needle like arrangement of pores in needle coke is shown below in Figure 2.1.

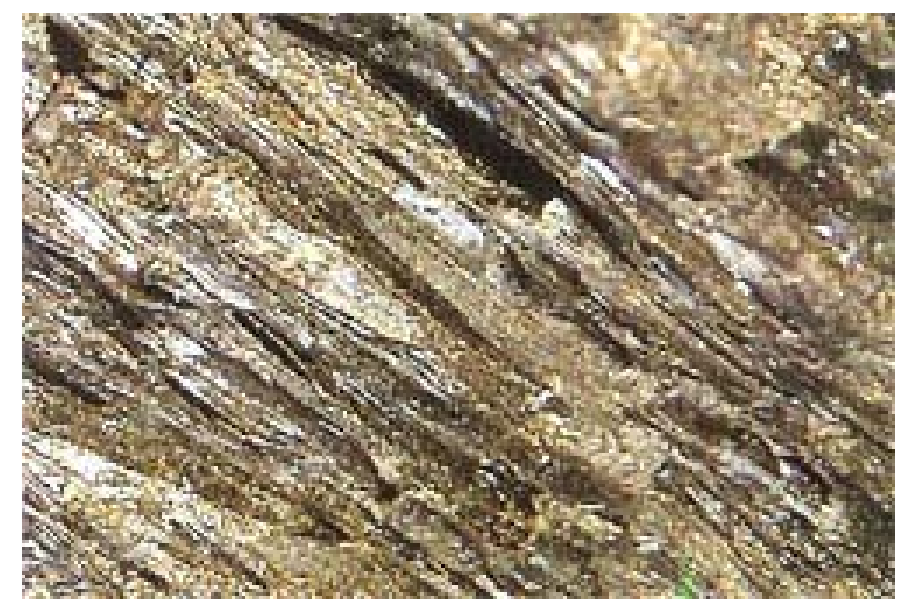

Figure 2.1 Cross-sectional view of needle coke

(Courtesy- Indian Oil Technologies Ltd)

Needle coke of high quality has been utilized as the essential filler of graphite electrodes for high performance in the electric arc furnace (EAF). This EAF method of making steel is more energy efficient than those of conventional steel making from iron ore. Needle coke has the highest value among those cokes produced world wide. Most of the coke produced (75 percent of total) is fuel grade coke for generating electricity; the second most produced coke is sponge coke (about 21 percent of total) for anode production in the aluminum smelting application. The rest of the coke production is needle coke for steel making [6]. The quality of the needle coke is an important factor for 
the mechanical strength and the electrical behavior of the graphite electrode. The specifications for a high quality needle coke are as follows

1. Low coefficient of thermal expansion, less than $1 \times 10^{-6} /{ }^{\circ} \mathrm{C}$

2. Low ash level, with a maximum of $0.15 \mathrm{wt}$ percent

3. Low sulfur and nitrogen content, less than $0.5 \mathrm{wt}$ percent

4. High real density, more than $2.12 \mathrm{gm} / \mathrm{cc}$

\subsection{OVERVIEW OF GRAPHITIZATION PROCESS}

Graphite electrodes are used primarily in the electric arc furnace for steel manufacture. They are also used in the refinement of aluminum and similar smelting processes. Graphite electrodes can provide high electrical conductivity and capability of sustaining the extremely high levels of generated heat and temperature [7].

A schematic of the procedure for making graphite electrode is shown in Figure 2.2. Premium quality calcined needle coke is hot-blended with binder pitch at around $120^{\circ} \mathrm{C}$ and the resulting plastic mass is extruded into "green" electrodes, which are then baked to over $800^{\circ} \mathrm{C}$. It takes 1 to 2 weeks to carbonize the pitch depending upon the size of the electrodes being made. The diameter of the electrode can reach 28 to 30 inches because of the large size required for the electric furnace.

Following coking, the baked electrodes are then impregnated with a special pitch to improve their density, mechanical strength, and electrical conductivity and to withstand the severe operating conditions in electric arc furnaces. They are then rebaked 
to carbonize the impregnation pitch and to drive off any remaining volatiles. The rebaked carbon electrodes are further processed in long electric resistance furnaces. Laid end-toend, or "longitudinally," the electrodes are heated to over $3000^{\circ} \mathrm{C}$ by passing an electric current through them. This ultra high temperature restructures the carbon to its crystalline form-graphite.

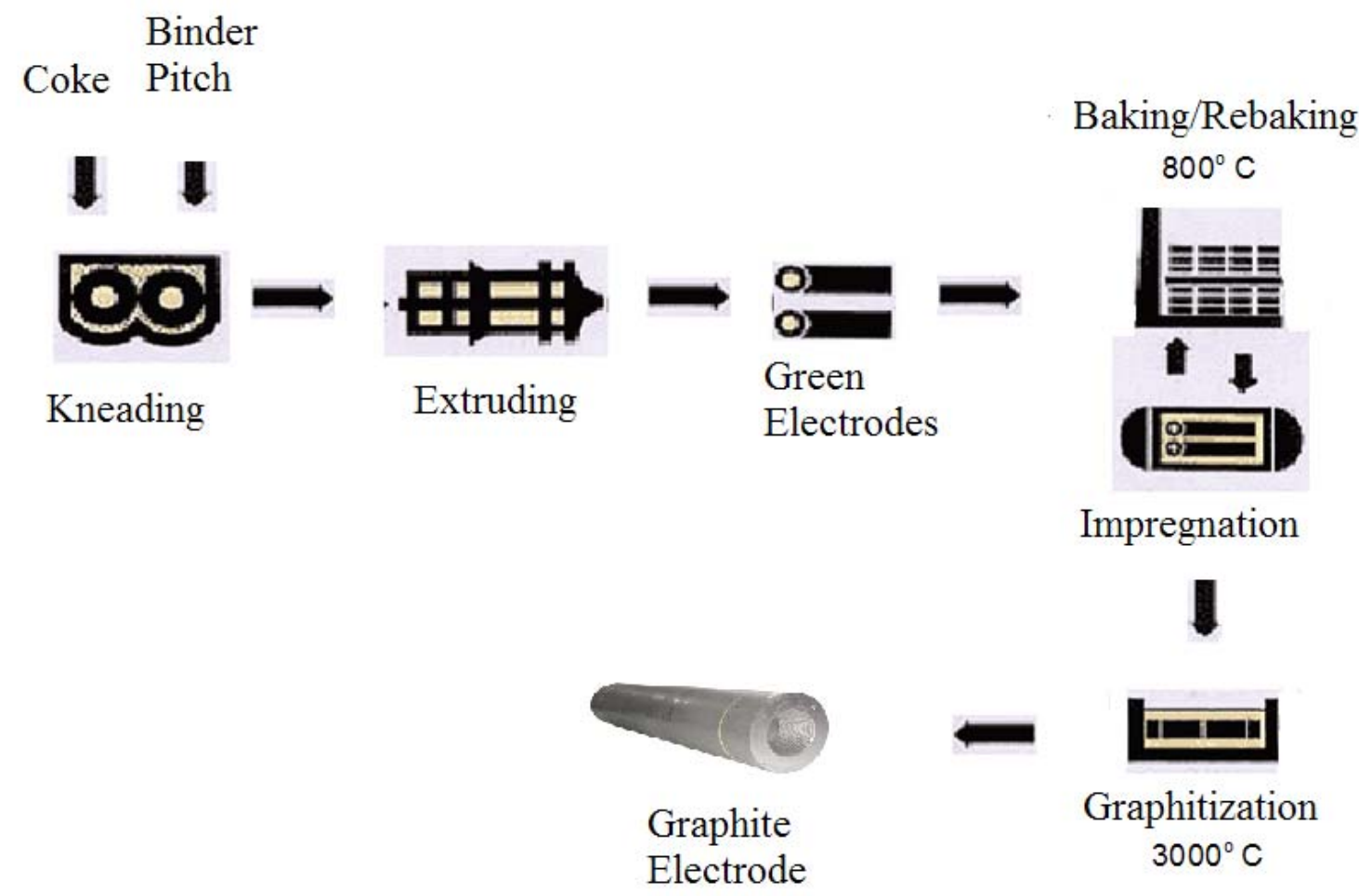

Figure 2.2 Making of graphite electrode

The Coefficient of Thermal Expansion (CTE) is of vital importance in the production of graphite for certain applications. Electrodes for the electric arc furnace must have a low CTE (less than $1 \times 10^{-6} /{ }^{\circ} \mathrm{C}$ ) to avoid excessive differential expansion at operating temperatures and the resultant spalling, which in turn causes excessive consumption of the electrode and cost in operation. Other applications (Ex: Nuclear Reactors) requiring dimensional stability at high temperatures are well-known although of somewhat less economic importance. 


\subsection{PUFFING}

The properties of the electrode are strongly governed by properties of coke. When carbon bodies made from such cokes are heated at temperatures in the vicinity of 2000$3000^{\circ} \mathrm{C}$, various sulfur and nitrogen-containing compounds decompose, attended by a rapid and irreversible expansion of the carbon body. This phenomenon is termed "puffing". Recently rapid heating for the graphitization of an electrode has been attempted to reduce electric cost in the longitudinal graphitization step. Rapid graphitization increases the extent of puffing because sulfur and nitrogen included as impurities in the needle coke vaporize very rapidly in a narrow temperature range causing irreversible expansion of coke. During the production of graphite articles, particularly high performance graphite electrodes, puffing is extremely undesirable, as it reduces the real density and physical strength of the electrode by destroying the structural integrity of the piece and renders it marginal or useless for its intended purpose.

Puffing of a carbon article made from high sulfur and nitrogen cokes generally starts at about $1500^{\circ} \mathrm{C}$, and may result in a volumetric expansion of as much as 25 percent. It is not simply an elastic expansion but is characterized as an inelastic, irreversible expansion.

The generally accepted explanation of the puffing phenomenon is that in acicular needle cokes with a relatively large amount of sulfur and nitrogen, sulfur and nitrogen atoms are bonded to carbon atoms by covalent bonds, either in carbon ring structures or linking rings. These bonds are less stable at high temperatures than the carbon-to- carbon 
bonds. On heating, the carbon-sulfur and carbon-nitrogen bonds rupture and the sulfur and nitrogen atoms are freed. The simultaneous rupture of these bonds and evolution of sulfur and nitrogen causes the physical expansion of the piece known as puffing. Thus these species need to be eliminated prior to coking and/or graphitization. [4] Improvement of coke properties is most desired.

\subsection{NEEDLE COKE FEEDSTOCKS}

There are two types of commercial needle cokes. These are coal-based and petroleum-based. Coal tar distillate is the coal-based feedstock and Decant oil is the petroleum-based feedstock.

\subsubsection{DECANT OIL}

The production of the pitch begins with the distillation of crude oil in petroleum refinery [9-11]. Crude oil is heated and fed into a fractionator, normally an atmospheric distillation column, in which the components are separated by boiling point to recover butanes and lighter hydrocarbons, light naphtha, heavy naphtha, kerosene, atmospheric gas oil, and reduced crude.

Table 2.1 Typical boiling point ranges of crude oil fractions ${ }^{[12]}$

Fraction Boiling Ranges, ${ }^{\circ} \mathrm{C}$

Butanes and Lighter $32-88$

Light Naphtha

$88-193$

Heavy Naphtha

193-271

Kerosene

271-321

Atmospheric Gas Oil

$321-427$

Light Gas Oil

610-427

Vacuum Gas Oil

427-566

Residua

$566+$ 
The reduced crude is then sent to a vacuum distillation tower to recover more naphtha, a vacuum gas oil stream, and a vacuum reduced crude bottoms or residua. Typically distillation cuts are shown in Table 2.1 .

To maximize profits, the refinery usually upgrades higher-boiling gas-oil distillates into lower-boiling naphtha distillates, or gasoline. This can be accomplished by sending the gas oils to a fluid catalytic cracking (FCC) unit in which heavy molecules are broken down into lower molecular weight compounds boiling within the naphtha range. After catalytic cracking, the light products are sent to a fractionator to separate the components by distillation. The heaviest fraction is then sent to a clarifier to remove entrained catalysts particles. Once most of the catalyst fines have been removed, the remaining heavy hydrocarbon product is called clarified cycle oil, also known as decant oil or slurry oil. A flow diagram of basic processes in a refinery is shown in Figure 2.3

The decant oil can be sent to a delayed coker unit to generate even more naphtha distillate and, if certain compositional requirements are met, a high-quality green needle coke. Alternatively, the decant oil can be further processed into petroleum-based pitch.

Comparison of two needle coke feedstocks in terms of composition through elemental analysis is given in Table 2.2. Coal-tar based needle coke has been proved to provide excellent coefficient of thermal expansion (CTE). However, the coke suffers a fatal problem of puffing during graphitization. 


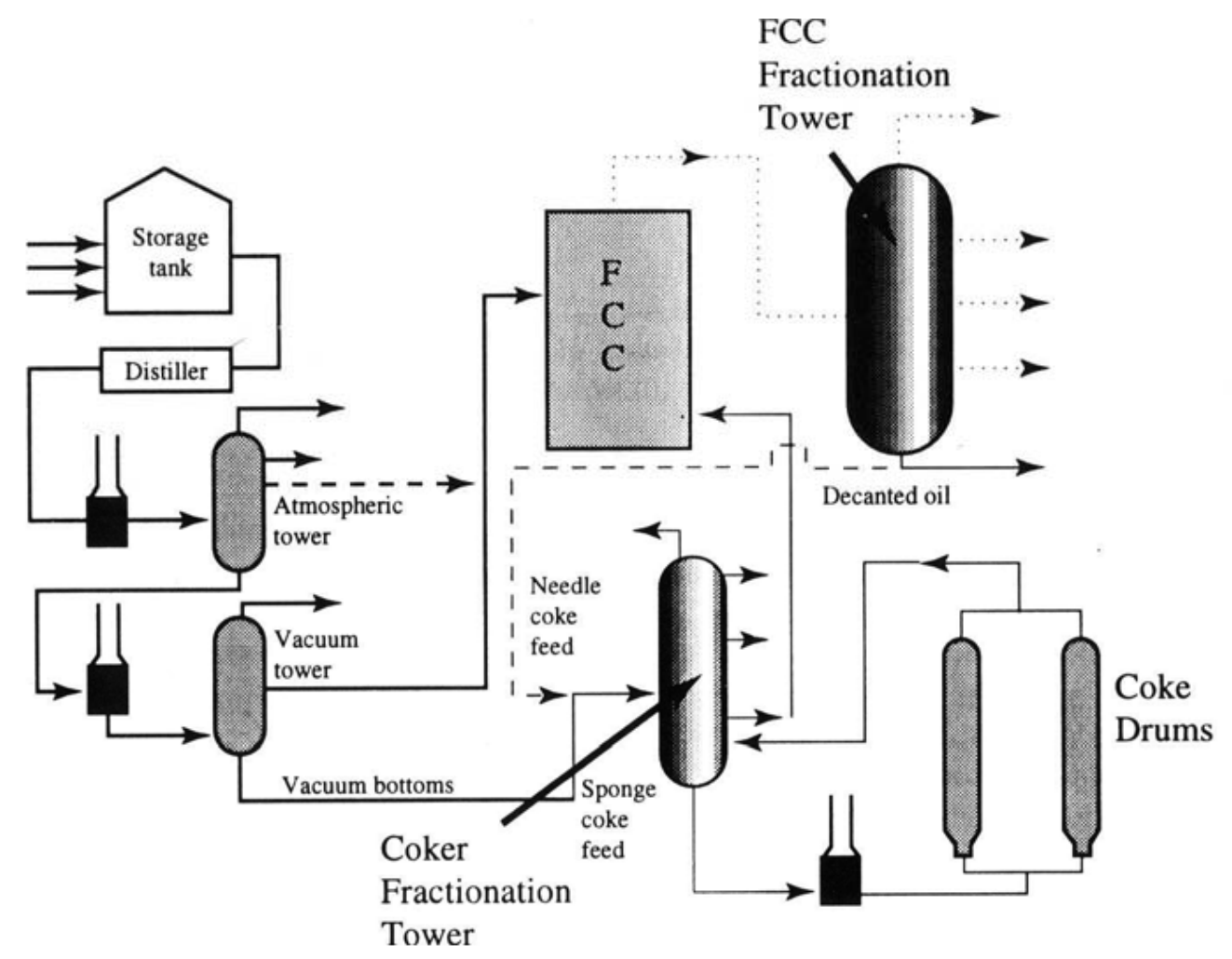

Figure 2.3Basic flow diagram of a modern petroleum refinery ${ }^{[10]}$

In the present study, Koppers coal tar distillate is selected as the needle coke precursor and tested for the removal of nitrogen using activated carbon.

Table 2.2 Elemental analysis of coal-tar and decant oil ${ }^{[6]}$

\begin{tabular}{|l|l|l|}
\hline & Coal Tar Distillate & Decant Oil \\
\hline Carbon & 92.72 & 91.68 \\
\hline Hydrogen & 5.81 & 7.86 \\
\hline Nitrogen & 1.11 & 0.44 \\
\hline Sulfur & 0.65 & 0.48 \\
\hline $\begin{array}{l}\text { Oxygen (by } \\
\text { difference) }\end{array}$ & -0.30 & -0.49 \\
\hline $\begin{array}{l}\text { H/C Atomic } \\
\text { Ratio }\end{array}$ & 0.75 & 1.02 \\
\hline
\end{tabular}




\subsubsection{COAL-TAR DISTILLATE}

Carbonization is a process by which coal is heated and driving off volatile products and liquids and leaving a solid residue called char or coke [13]. During the production of metallurgical coke, coal tar is formed as a by-product by capturing the volatiles and condensing them. Coal tars are complex mixtures of phenols, polycyclic aromatic hydrocarbons and heterocyclic compounds. Carbon feedstocks such as naphthalene, tar acids, tar bases, coal tar pitch, etc. can then be obtained from the processing and distillation of the coal tar produced during the manufacture of metallurgical coke. Coal tar pitch is a black or dark-brown aromatic residue produced by the distillation or heat treatment of coal tar. It is a solid at room temperature and exhibits a broad softening range instead of a defined melting temperature. Coal tar pitch has many uses in industry and in consumer products. Coal tar pitch is primarily used as the binder for aluminum smelting electrodes. It is also used in roofing materials, to impregnate and strengthen refractory bricks for furnaces, in surface coatings, and black varnishes for protective coating for industrial steelwork. Coal tar pitch is also incorporated as the carbon component in electrodes, carbon brushes, and carbon and graphite articles.

A modern byproduct coke plant is composed of extensive hardware for the high temperature carbonization of coal and recovery of evolved gases, oils, tars, and other useful chemicals [14]. The coke plant is made up of many brick-lined ovens arranged into batteries in which each coke oven is a long and narrow rectangular chamber ranging in size from 35 to 45 feet long, 9 to 15 feet high, and 1 to 2 feet wide. The temperature of 
the oven walls is maintained at about $2000 \mathrm{~F}$ by the combustion of fuel gas that is generated by the carbonizing coal itself. On top of each oven along its length are several evenly spaced holes sealed with removable lids. During charging, the lids are removed and coal is dropped through the openings by means of a coal-charging or larry car to initiate the coking cycle. Immediately after filling the oven with coal the lids are replaced. After several hours the coal has been carbonized completely. Finally, the two ends of the oven are opened, and the coke pushed out to cool on a loading platform and the oven is made ready for another cycle. Within the incandescent oven environment, the coal nearly immediately starts to decompose thermally upon introduction. The passage of decomposition products and volatiles through the hot coke bed and along the oven walls and ceiling causes extensive cracking to occur. These volatile products are removed from each individual oven by means of an ascension pipe that extends from the roof of the oven to a gas-collecting main. Within the top portion of the ascension pipe are sprays of flushing liquor, a dilute ammonia solution, to condense tar from the gas. Within the collecting main about $70 \%$ of the tar, called heavy tar, is condensed. The gas and vapors, heavy tar and flushing liquor leave the collecting main at about $100^{\circ} \mathrm{C}$ and are sent to a downcomer to effect gas-liquid separation. One exit stream of the downcomer contains the heavy tar and flushing liquor, which are sent to a decanter. The decanter separates the heavy tar from the flushing liquor by gravity so that the heavy tar can be pumped to storage and the flushing liquor recycled. The remaining $30 \%$ of the tar is carried along with the coke oven gas through the other exit stream of the downcomer to a primary cooler to condense most of the light tar from the gas stream. Further operations are required to recover additional light tar and to purify the gas for heat generation on site or 
for sale. Figure 2.4 gives an overview of the carbonization process through which coal tar distillate is produced.

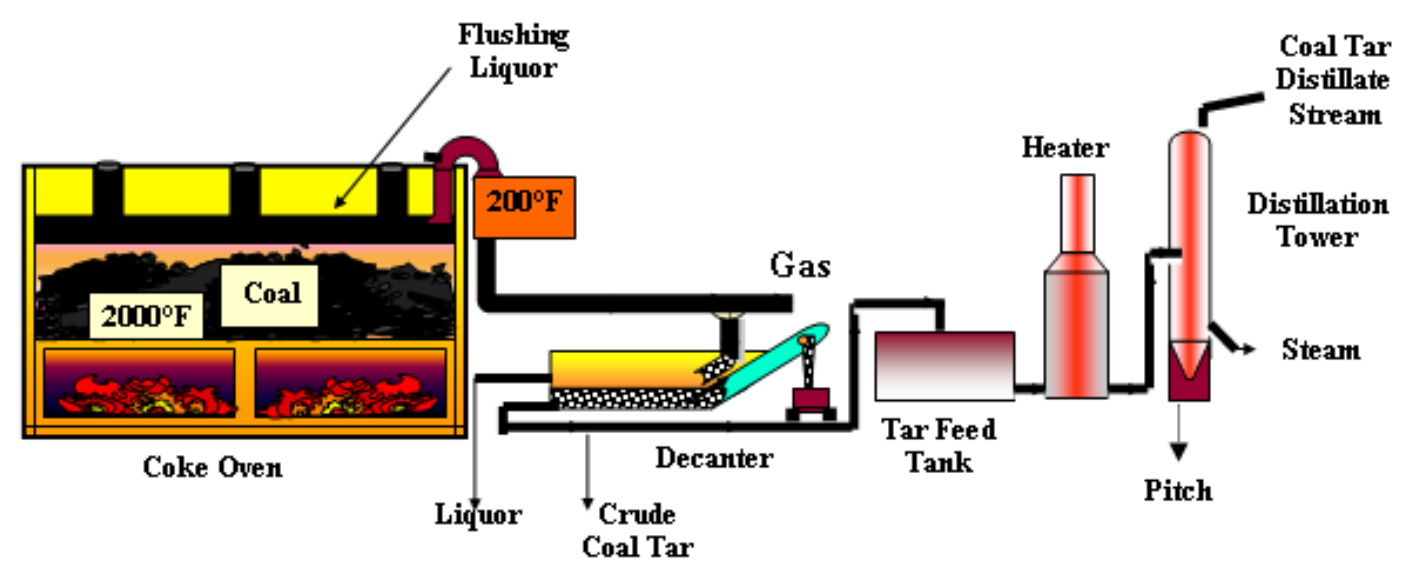

Figure 2.4 Production of coal tar distillate ${ }^{[13]}$

The heavy tar is transferred from a heated storage tank to a dehydrating flash unit (Heater) at atmospheric pressure whereby light oil and water are vaporized. Flash units are used to prevent fouling of the distillation columns by the tar. The light oil is sent back to the dehydrating unit as reflux. All subsequent operations are conducted under vacuum. The dehydrated tar is heated and then sent to a flash unit to drive off volatile compounds, which are sent to the fractionating column. The liquid residue (top tar) is heated to a higher temperature before entering the secondary flash unit to strip all components except the pitch. The light compounds from the flash units are sent to a series of distillation columns, each column equipped with its own reboiler, and each succeeding column operating at higher temperature. Through this separation process the entire range of coaltar distillates and pitch is made, as indicated in Table 2.3. 
Distillation fractions and residues from high-temperature coal tars are used for the construction of roads and in the production of naphthalene, recovery of benzene, production of anthracene oil and smokeless solid fuel, impregnation of electrodes, fibers, carbon composites, carbon foams, and manufacture of electrodes, carbon nanofibers, nanotubes and graphite.

From a metric ton of coal, a modern by-product coke oven yields about 600-700 $\mathrm{kg}$ of coke, $300-360 \mathrm{~m}^{3}$ of gas, $10-15 \mathrm{~L}$ of light oil, and $30-50 \mathrm{~L}$ of coal tar, $60-85 \mathrm{~kg}$ of chemicals, mostly ammonium compounds [13].

Table 2.3: Coal-tar distillation fractions ${ }^{[14]}$

\begin{tabular}{lcc}
\hline Tar fraction & Boiling range, ${ }^{\circ} \mathrm{C}$ & Major Component \\
\hline Light oil & To 210 & Benzene, Toluene, Xylene, Solvent \\
Middle oil & $210-230$ & Naphtha, Tar acids \& bases \\
Methylnaphthalene & $230-270$ & Tar acids \& bases, Naphthalene \\
Light creosote & $270-315$ & Mixed methylnaphthalenes \\
Middle creosote & $315-355$ & Acenaphthene, Fluorene \\
Heavy creosote & $355-450$ & Phenanthrene, Anthracene \\
Flouranthene & & Pyrene, Chrysene, and \\
Coal tar pitch & Above 450 & Complex condensed aromatics \\
\hline
\end{tabular}




\subsection{ACTIVATED CARBON STUDIES}

\subsubsection{ACTIVATED CARBON}

Activated carbons are characterized as having a large internal surface area and a specific pore structure. Activated carbons are noteworthy for their ability to selectively adsorb molecules from both liquids and gases. Activated carbons are typically produced by thermal activation at elevated temperatures whereby carbon is treated in an oxidizing atmosphere (i.e. steam, air and carbon dioxide). The resulting burn-off leads to a highly porous structure. Some uses of activated carbon include water purification, gas/liquid separation, catalyst production and in the area of the electric double layer capacitor. For most applications activated carbon is exploited for its ability to remove selectively certain molecular constituents, while leaving other constituents behind [21].

Activated carbon is produced from nearly all carbon-containing organic materials, mainly wood, sawdust, nutshells, fruit stones, peat, lignite, coal, petroleum coke, etc. The use of a suitable precursor is mainly conditioned by its availability and cost, although it also depends on the main applications of the manufactured carbon and the type of installation available [22].

\subsubsection{METHODS OF ACTIVATION}

Activated carbon can be prepared through two methods i.e., Physical activation and Chemical activation. The basic flow sheet for the manufacture of activated carbon is shown in Figure 2.5. 
The activation reaction in physical activation is highly endothermic. Below $700^{\circ} \mathrm{C}$ the oxidation is very slow especially with $\mathrm{CO}_{2}$. Some studies indicate the porosity and the surface area of devolatilized coal char samples do not show a considerable change below about $900{ }^{\circ} \mathrm{C}$, but they increase significantly as the reaction proceeds above this temperature $[15,16]$.

The preparation process of activated carbon by physical activation consists of carbonization of coal or other carbonaceous material in nitrogen followed by activation of the resulting chars in $\mathrm{CO}_{2}$ or steam. Experimental results reveal that the surface area, pore volume and average pore diameter of the activated carbon generally increase with the amount of carbon burn-off carried out at the same temperature. These surface characteristics are also influenced by the variation of activation temperature [17]. Above $1100{ }^{\circ} \mathrm{C}$ the carbon material deteriorates and the resulting surface areas will be low. Usually the activation is done for about $4-12 \mathrm{hrs}$ when carbon dioxide is used and about $1 / 2$ to $2 \mathrm{hrs}$ when steam is used. Controlling of activation is difficult in the case of steam $[14,20]$. One can determine experimentally by varying the operating conditions such as temperature, time of activation and $\mathrm{CO}_{2}$ flow rate, specific operating temperature and time at which the maximum activity or surface area per gram of active carbon can be obtained. Moreover carbon is a poor thermal conductor so to maintain low temperature gradients radially the activation tubes must be small in at least one dimension.

The other method, chemical activation, involves the carbonization of the material of vegetable origin such as wood waste, with the addition of activating agents which influence the course of pyrolysis and restrict the formation of tar. The amount of aqueous 
phase compounds in the distillate (acetic acid, methanol, and others) is also less than in normal carbonization. In this way good activated carbon can be prepared in a single operation. The temperature needed for pyrolysis is also lower and usually carried out at temperatures from 400 to $1000{ }^{\circ} \mathrm{C}$. The most widely used activation agents are zinc chloride, potassium sulfide, potassium thiocyanate, phosphoric and sulfuric acids. Sometimes hydroxides of alkali metals, magnesium and calcium chloride and other substances are used.

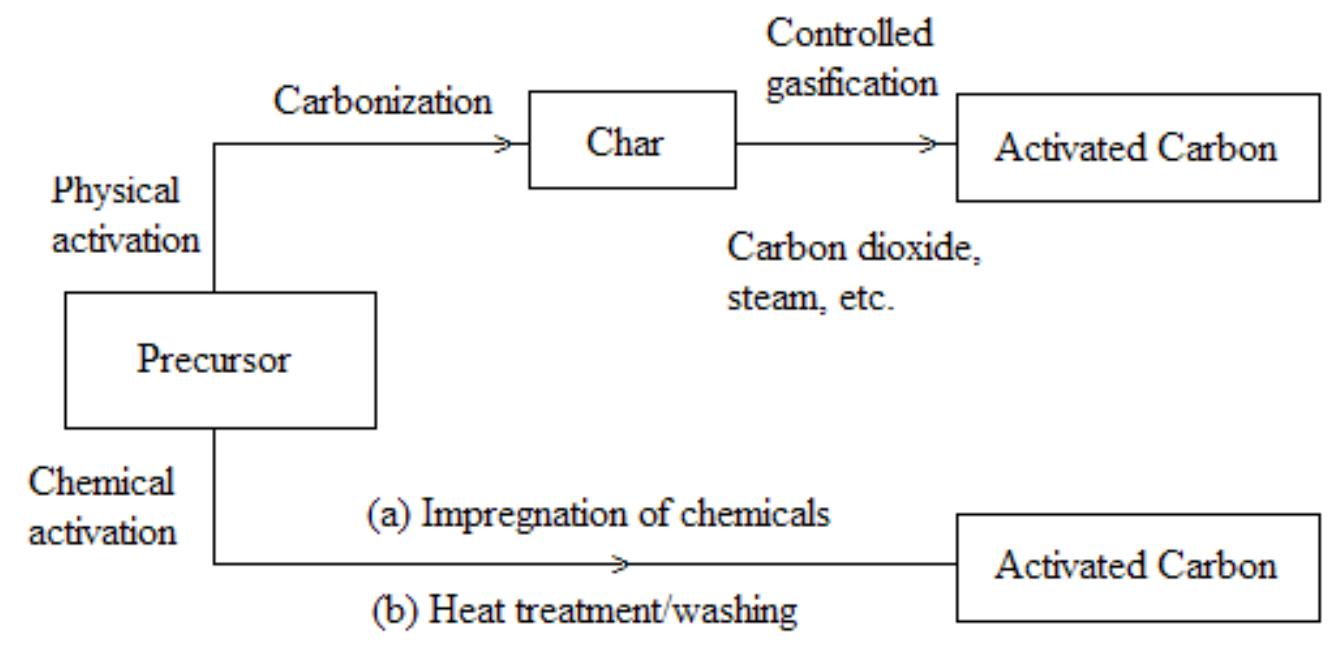

Figure 2.5 General flow sheet for manufacture of activated carbon

In the process of chemical activation, most of the non-carbon elements such as hydrogen and oxygen are first removed in gaseous form during carbonization by pyrolytic decomposition. The freed atoms of elemental carbon are grouped into elementary graphitic crystallites. The irregular crystallites and their interstitial spaces are filled or blocked with amorphous carbon. This material will have only a small adsorption capacity. To get a large adsorptive capacity, the material must be activated in such a way that the activation agent reacts with the carbon. Chemical activation takes place in two stages. In the initial stage with less than about ten percent burn-off, the amorphous carbon 
is preferentially reacted away and the interstitial spaces opened. Subsequently, carbon of the crystallites is reacted and the pore structure begins changing. During the process of activation, the spaces between the elementary crystallites become cleared of nonorganized carbon and partially from the graphitic layers of the crystallites. The activation

process causes an enormous number of pores to be formed so that the total surface area of the pore walls become very large. It is very difficult to get accurate information on the actual shape of the pores so they are generally treated as cylindrical capillary structures, and a tortuosity factor is taken while analyzing the experimental results [18].

\subsubsection{POROUS STRUCTURE}

As shown in Figure 2.6, the pores in activated carbon are usually divided into three size groups $[18,19]$, i.e.

a) Micro pores, pore size $<2 \mathrm{~nm}$ and volume 0.15 to $0.5 \mathrm{ml} / \mathrm{g}$

b) Transitional or meso pores, pore size 2 to $50 \mathrm{~nm}$ and volume $0.02-0.1 \mathrm{ml} / \mathrm{gm}$

c) Macro pores, pore size $>50 \mathrm{~nm}$ and volume $0.2-0.5 \mathrm{ml} / \mathrm{g}$

The pore volume depends on the type of carbon material used for activation. Each of these three pore groups has a specific function in the process of adsorption. Micropores because of their large surface area and volume determine the overall adsorptive capacity of the activated carbon. Transitional pores serve as sites for condensation under sufficiently high pressure and provide passage to the micropores since the micropores generally do not lead directly to the outer surface. The macropores in turn allow access to the transitional pores and hence to the micropores. Because of 
their small area, the macropores are relatively insignificant in terms of the amount of adsorbate retained there, but they may play a significant role as places for catalyst deposition when activated carbon is used as a catalyst support. The adsorptive properties of active carbon are determined not only by its porous structure, but also by its chemical composition. The elements that are chemically bonded, principally hydrogen and oxygen, are derived from the starting material and remain in the structure of the active carbon as a result of imperfect carbonization or become chemically bonded during the activation step [19].

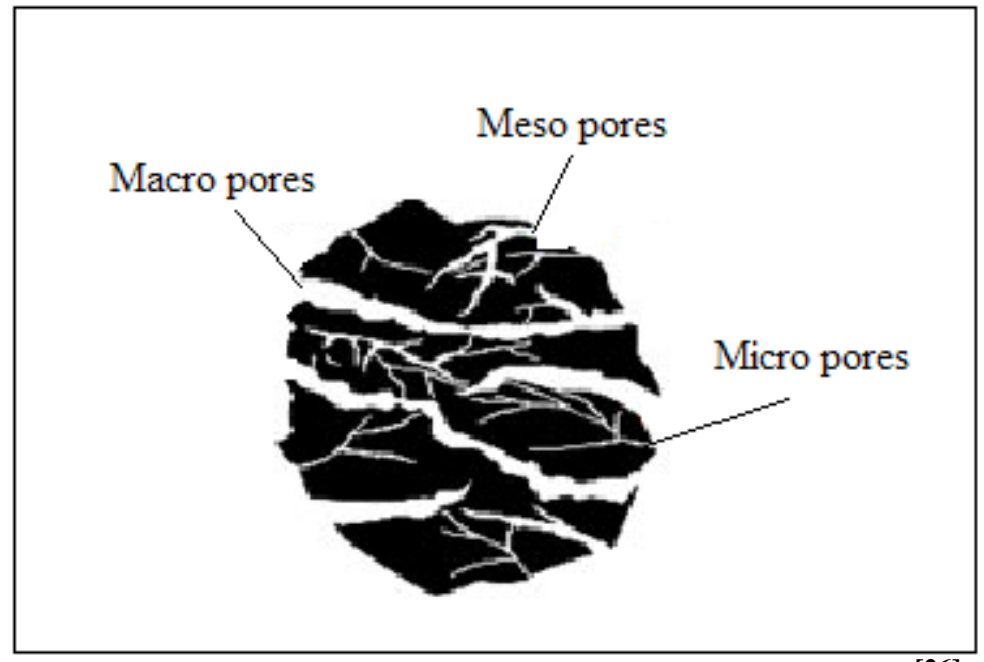

Figure 2.6 Activated carbon structure- schematic ${ }^{[26]}$

\subsubsection{COMMERCIAL ACTIVATED CARBONS}

Commercial activated carbons are available in three forms i.e., powdered, granular and pelletized activated carbon as shown in Figure. 2.7. Powdered carbons are used for adsorption from solution. Disintegration into fine particles enhances the rate of establishment of adsorption equilibrium, which proceeds very slowly in liquids because of the low rate of diffusion. These powdered carbons include the active carbons for the 
removal of coloring matter from solution, and medicinal carbon. Powdered active carbon is usually produced by activating lump material, chips of wood charcoal, or lumps of paste prepared by mixing saw-dust with a solution of zinc chloride, and subsequently grinding the activated product.

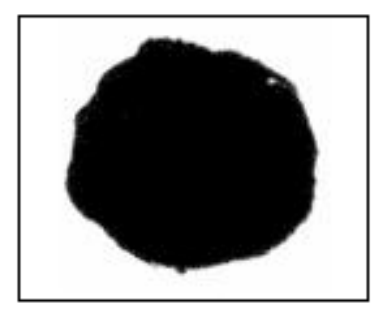

A

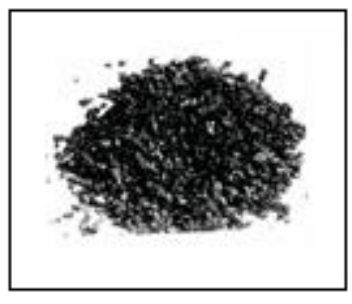

B

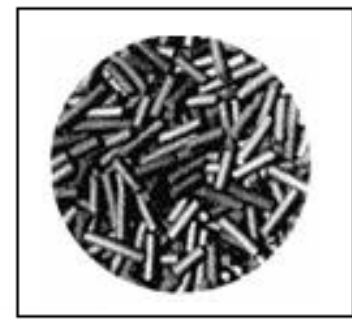

C

Figure 2.7 Forms of activated carbon. A-Powdered form, B-Granular form and C-Pelletized form.

Granulated activated carbons are used mainly for adsorption of gases and vapors and are therefore known also as gas-adsorption carbons. Adsorption from the gaseous phase takes place under dynamic conditions by making the mixture of adsorbate and carrier gas pass through a bed of activated carbon where the gas contacts the carbon surface and adsorbs. Granulated activated carbons are prepared by activating a lump material such as carbonized shells, husks, fruit stones, crushed wood charcoal, etc., with a gaseous agent such as steam or flue gas $\left(\mathrm{CO}_{2}\right)$. The final phase of the production is the adjustment of the grain size of the active product by crushing and classification. Granular carbon can also be obtained by chemical activation.

Pelletized activated carbon is produced as uniform cylindrical shapes. The starting material is prepared in the form of a plastic mass, extruded from a die and the rod is cut into pieces of uniform length. In chemical activation the plasticized mass is mixed with 
an activation agent $\left(\mathrm{ZnCl}_{2}\right)$ and the pressed shapes acquire necessary hardness by a heat treatment associated with activation. In the case of physical activation, the plastic mass is prepared by thorough kneading of a finely ground carbonaceous starting material such as coke, natural coal, or wood-charcoal with tar. During the thermal processing of the pressed shapes most of the tar distills off, but the residue is pyrolysed to give a binding material, which holds the grains into a compact mass. The advantage of this method of production is uniformity of shape, which improves the distribution of the gas stream over the cross section of the carbon layer in a gas adsorber [20]. However, the quality of the resulting activated carbon is considerably influenced by the starting material.

\subsubsection{IMPORTANCE OF SURFACE FUNCTIONAL GROUPS}

Activated carbons have been proven to be effective adsorbents for the removal of a variety of organic and inorganic pollutants dissolved in aqueous media or from gaseous environments. Their large sorption capacity is linked to their well-developed internal pore structure, surface area and the presence of a wide variety of surface functional groups. The existence of surface functional groups on the carbon matrix therefore implies they can be manipulated by thermal or chemical treatments to produce adsorbents that are tailored for particular functions [24]. Recent studies on the effect of surface functional groups on adsorption capacity of activated carbons have proved that surface modification of activated carbons is of vital importance in improving their adsorption performance.

For example, Y.H.Li et al. [25] studied the effect of varying physical and

chemical properties of activated carbons on adsorption of elemental mercury $\left(\mathrm{Hg}^{0}\right)$ and 
observed that both lactone and carbonyl groups are the likely active sites for $\mathrm{Hg}^{0}$ adsorption. They also found that the carbons having lower $\mathrm{CO}$ to $\mathrm{CO}_{2}$ ratio and a low phenol group concentration tend to have a higher $\mathrm{Hg}^{0}$ adsorption capacity. The results suggest that mercury adsorption capacity has a strong dependence on the sample's chemical characteristics. In another study, Karatepe et al. [26] observed that the carbon samples whose surfaces are treated with HCL and HF adsorbed more sulfur dioxide when compared with their untreated counterparts. Their experimental results showed that the phenolic and lactone groups play an important role in $\mathrm{SO}_{2}$ adsorption. The above two studies suggests that certain functional groups are responsible for the high/low adsorption capacity of carbons for certain chemical compounds. From the second study it can be observed that Karatepe et al. have modified the surface functional groups of original activated carbons by oxidizing those using HCL and HF acids and thus increased their adsorption capacity. And the work by song et al [28] showed that activated carbon is a candidate adsorbent for removing sulfur species from diesel fuel and the oxidation modification of activated carbon changes their adsorptive desulfurization capacity significant. 


\section{CHAPTER 3: EXPERIMENTAL}

\subsection{MATERIALS}

Two kinds of activated carbons were selected as adsorbents for the nitrogen species from the Koppers coal-tar distillate. They are the Nuchar SA 20 and the WVUAC $900-15$. Nuchar SA 20 is a powdered activated carbon with the surface area $1569 \mathrm{~m}^{2} / \mathrm{gm}$ and an average pore size $3 \mathrm{~nm}$. The second activated carbon, WVUAC 900-15, is a granular coal-based activated carbon prepared at West Virginia University. The new fluidized bed reactor system which was designed and constructed in the Chemical Engineering laboratory as a part of a companion research project is used to prepare WVUAC $900-15$. This activated carbon has a surface area of $1400 \mathrm{~m}^{2} / \mathrm{gm}$ of an average pore size of $2.7 \mathrm{~nm}$. The other materials used in this research work are toluene, carbon disulfide and tetrahydrofuran as solvents to dilute the Koppers coal-tar distillate. Nitric acid is used as the oxidizing agent for improving the surface properties of activated carbons.

\subsection{INSTRUMENTS}

The three important instruments incorporated in this research work are the elemental analyzer (Flash EA 1112), the Accelerated Surface Area and Porosimetry analyzer (ASAP 2020), and a Precision Shaking (Model 25) Water Bath. A brief description of each instrument and the analytical technique behind the instrument is given below. 


\subsubsection{FLASH ELEMENTAL ANALYZER 1112}

The elemental analyzer, Flash EA 1112, measures nitrogen levels in CTD before and after treating it with activated carbon. The Flash EA 1112 is capable of measuring the elements Carbon, Hydrogen, Nitrogen and Sulfur but for this work it was configured for nitrogen analysis alone.

An Auto Sampler (AS) is connected to a quartz reactor (R) placed in a furnace at the temperature of $900^{\circ} \mathrm{C}$. The reactor outlet in turn is connected to the filter $(\mathrm{F})$. The filter outlet is connected to an analytical gas chromatographic column (CC), and in turn connected to the thermal conductivity detector (TCD). The schematic diagram of the nitrogen analysis system is shown in Figure 3.1.

A brief description of the procedure followed to analyze percentage of nitrogen from the carbon treated Coal Tar Distillate is given as follows: The sample is weighed in a tin capsule before being loaded into Auto Sampler AS to the nearest microgram with an approximate sample weight of 2-3 micrograms. Oxygen flows into the combustion reactor $\mathrm{R}$ for a preset time. After a few seconds, the sample stored in the auto sampler is dropped into the combustion reactor. When tin comes in contact with the extremely oxidizing environment, it triggers a strong exothermic reaction. The sample temperature rises to approximately $1800^{\circ} \mathrm{C}$ instantly causing the sample combustion. At the end of the time set for oxygen introduction, the gas flow switches to helium. The gas mixture $\left(\mathrm{NO}_{\mathrm{x}}, \mathrm{CO}_{2}, \mathrm{H}_{2} \mathrm{O}\right)$ generated by combustion is conveyed across the reactor $\mathrm{R}$ where the 
oxidation of components is completed and nitrogen oxides formed are reduced to elemental nitrogen. Then the gas mixture passes across a trap, containing two adsorption filters combined into a single filter, $F$. The first half of the filter $F$ is packed with magnesium per chlorate which retains moisture. The second half of the filter F, which is packed with soda lime, removes carbon dioxide from the gas mixture. Nitrogen is then separated in the chromatographic column $\mathrm{CC}$ and conveyed to the thermal conductivity detector TCD that generates an electrical signal proportional to the concentration. The signal is then processed by the Eager 300 software to provide the nitrogen percentage.

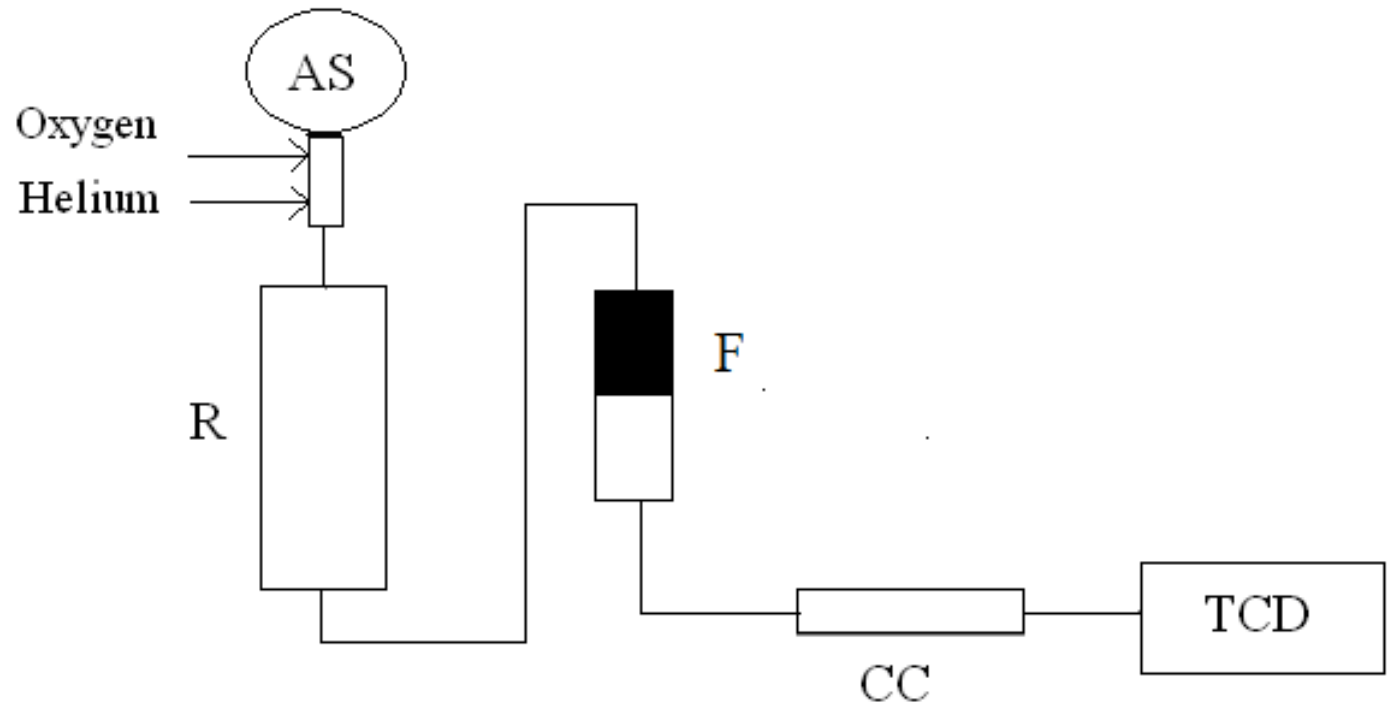

Figure 3.1 Schematic diagram of the elemental analyzer set up for nitrogen analysis

For the calibration of the instrument, two samples with different nitrogen composition are available.

Standard\#1: Lubricant Oil containing 1.06 weight percent of nitrogen

Standard\#2: Soil containing 0.36 weight percent of nitrogen 
Four empty tin capsules were passed through the reactor as blanks to check the background nitrogen measurement from the oxidation of tin. A small nitrogen peak shows up in the chromatograph which is suspected to be caused by some atmospheric nitrogen which enters into the reactor R from the sample chamber AS. The instrument is calibrated using 3 tin capsules filled with a standard, each time before analysis. The nitrogen measured from the blank run is subtracted from the nitrogen measured from the sample to correct for the background. The unknown sample is measured in the instrument four times. The results from the four runs are then averaged and reported as the final result as weight percent of nitrogen in the sample.

\subsubsection{ACCELERATED SURFACE AREA POROSIMETRY 2020}

The surface area and the pore volume of both the commercial activated carbon and the carbon prepared at WVU were analyzed using the Accelerated Surface Area and Porosimetry analyzer, ASAP 2020. This instrument uses the nitrogen gas sorption technique to generate high-quality data on adsorption and desorption of gas by the sample [29]. The theory behind the analytical technique as follows: a sample contained in an evacuated sample tube is cooled (typically) to cryogenic temperature and then exposed to analysis $\left(\mathrm{N}_{2}\right)$ gas at a series of precisely controlled pressures. With each incremental

pressure increase, the number of gas molecules adsorbed on the surface increases. The pressure at which adsorption equilibrium occurs is measured and the universal gas law is applied to determine the quantity of gas adsorbed. 
As adsorption proceeds, the thickness of the adsorbed film increases. Any micropores in the surface are quickly filled, then the free surface becomes completely covered, and finally larger pores are filled. The process may continue to the point of bulk condensation of the analysis gas. The desorption process then begins in which pressure systematically is reduced resulting in liberation of the adsorbed molecules.

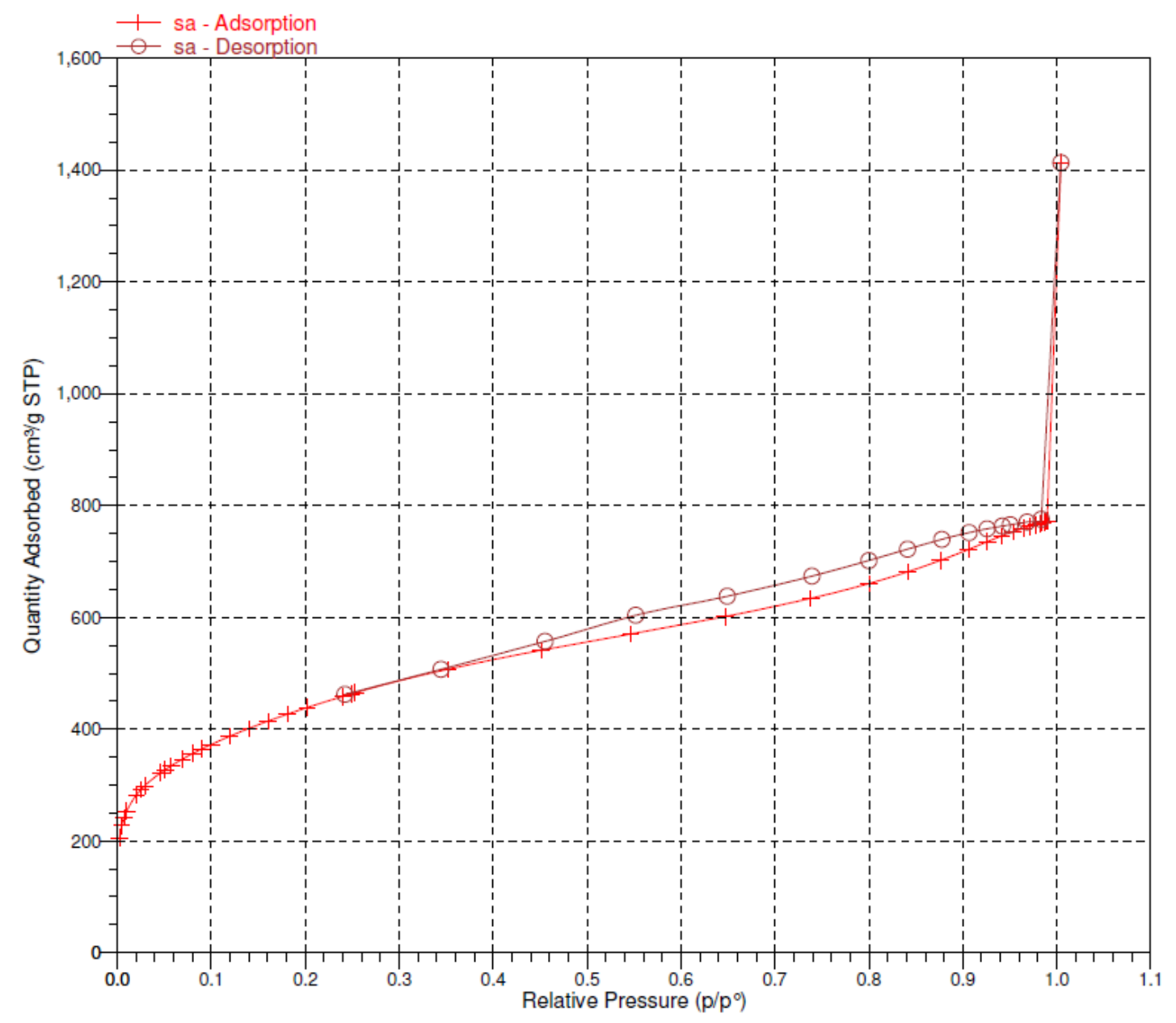

Figure 3.2 Isotherm linear plot for Nuchar SA20 
As with the adsorption process, the changing quantity of gas on the solid surface is quantified. These two sets of data describe the adsorption and desorption isotherms. A typical isotherm is plotted (as shown in Figure 3.2) as the amount of adsorbed nitrogen versus the adsorptive pressure. Usually, the pressure is expressed as a ratio of the adsorptive pressure, $\mathrm{P}$, to the saturated vapor pressure over the bulk liquid, $\mathrm{P}_{\mathrm{o}}$. Analysis of the isotherms yields information about the surface characteristics of the material.

There are two principal methods to measure the isotherm, volumetric and gravimetric. In both methods the adsorbent is held at constant temperature around boiling point of adsorptive. The adsorptive pressure is increased step-wise and held constant for a period of time to allow adsorption to occur and the temperature of the adsorbent to reequilibrate. The time length required depends upon the physical arrangement and the system being studied.

\subsubsection{SHAKING WATER BATH}

The Precision shaker bath, shown in Figure 3.3, was used to keep the activated carbon suspended in solution of the CTD and the solvent. The shaker bath consists of an orbital shaking plate which is submerged in a water bath. The shaking plate was provided with metal holders to hold the volumetric flasks tightly at any speed of the plate. The temperature $\left({ }^{\circ} \mathrm{C}\right)$ of the water bath and the speed (rpm) of the shaking plate can be controlled precisely through out the experiment to optimize the interaction of CTD and activated carbon. A total of six singles could be treated in the shaker bath at one time. 


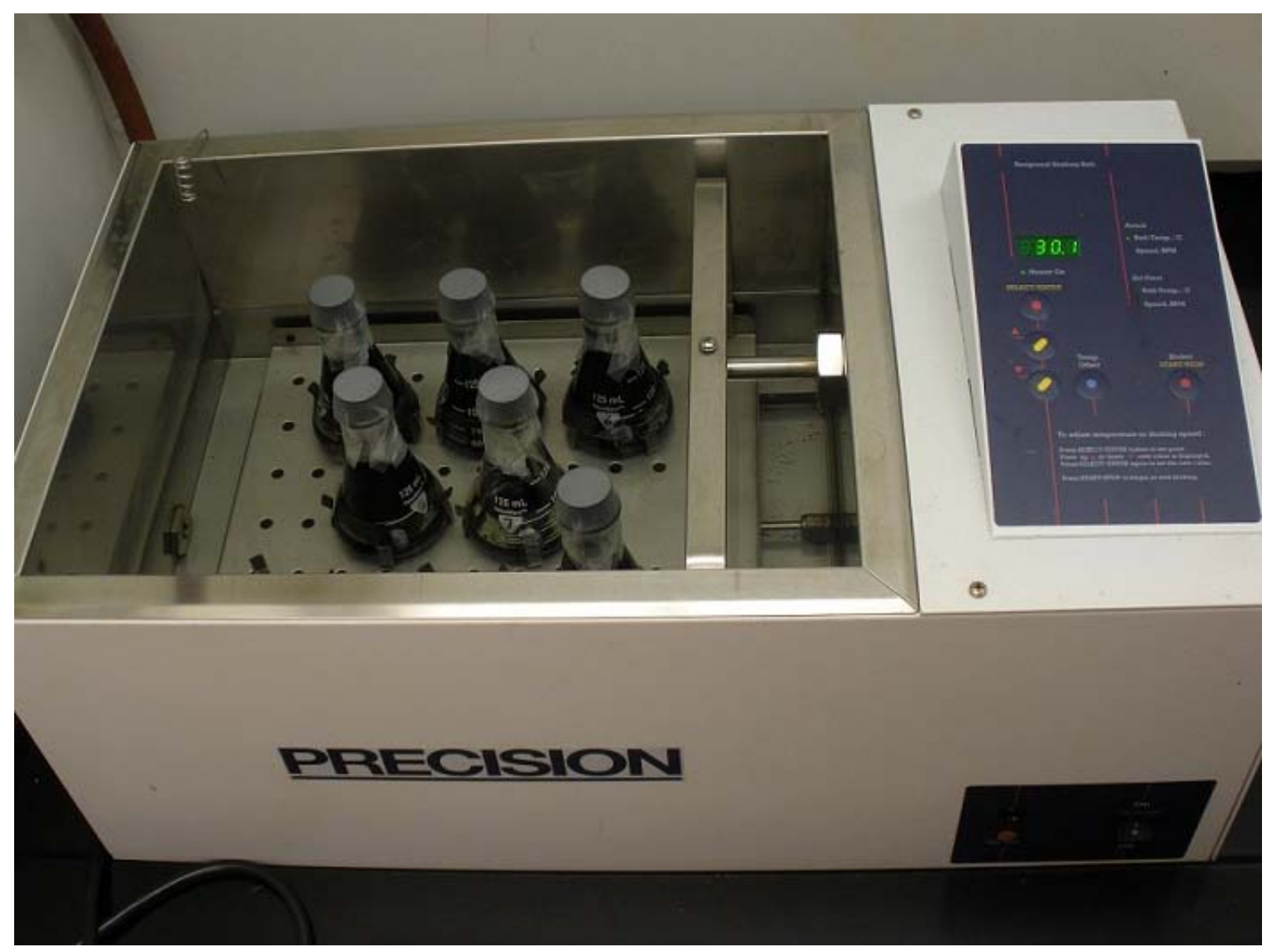

Figure 3.3 Experimental setup showing shaker bath with sample flasks

\subsection{EXPERIMENTAL METHOD}

\subsubsection{SELECTION OF SOLVENT}

Since coal tar distillate (CTD) is a highly viscous substance at operating temperature, it needs to be diluted to facilitate contacting it with the activated carbon.

An experiment was conducted to determine the mass balance of coal tar distillate. A 50 gm sample of solution with 3:1 wt ratio of CTD to toluene was prepared in $125 \mathrm{ml}$ flask and was placed in the shaker bath which was agitated at $165 \mathrm{rpm}$ and at a constant temperature of $30^{\circ} \mathrm{C}$. After one hour the flask was taken out and centrifuged for $10 \mathrm{~min}$ 
at $2000 \mathrm{rpm}$. It was observed that some undissolved particles of CTD were separated from the solution and deposited at the bottom of centrifuge tubes. These particles were not visible in a freshly prepared solution nor were they detected after centrifugation with carbon added to the solution. Figure 3.4 shows the solubility of CTD in toluene at 1:1, 2:1, 3:1, 4:1 and 5:1 solvent to CTD wt ratios in flasks labeled as 1, 2, 3, 4 and 5 respectively.

Some of the undissolved particles of CTD can be seen on the flask walls

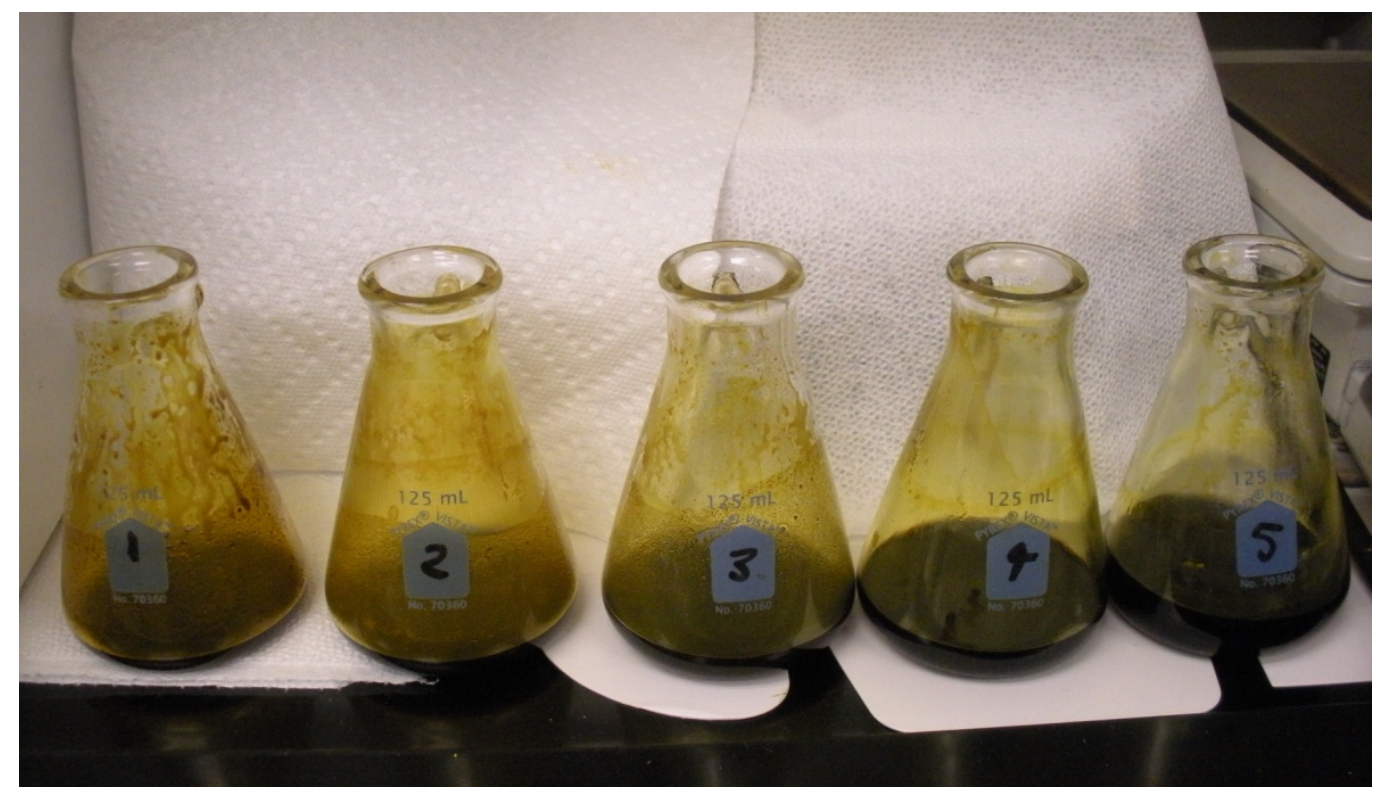

\section{Figure 3.4 Solubility of CTD in toluene at 1:1, 2:1, 3:1, 4:1 and 5:1 toluene to CTD wt ratios}

These undissolved particles accounted for about 30 percent of the weight of the original CTD. The recovered solution was filtered and the toluene evaporated. The resulting recovered CTD was then sent for nitrogen analysis. The nitrogen content of the recovered CTD was reduced by 26 percent even without treating with carbon. Thus it was determined that some nitrogen compounds were being removed in the form of 
undissolved particles by centrifugation. So it was deemed necessary to search for another solvent and the proper solvent-to-CTD ratio to dissolve completely the CTD.

Three candidate solvents were chosen to dissolve the coal tar distillate based on their boiling points and solubility properties. These solvents are listed in Table 3.1.

\section{Table 3.1 Boiling points of various solvents}

\begin{tabular}{|c|c|c|}
\hline & Solvent & $\begin{array}{c}\text { Boiling } \\
\text { point, }{ }^{\circ} \mathrm{C}\end{array}$ \\
\hline 1 & Toluene & 110.6 \\
\hline 2 & Carbon disulfide $\left(\mathrm{CS}_{2}\right)$ & 46.0 \\
\hline 3 & Tetra hydro furan (THF) & 66.0 \\
\hline
\end{tabular}

A solvent with a low boiling point has an advantage of quick evaporation from solution leaving behind the CTD. Since constant weight of the sample is an important condition in the nitrogen analysis step, it is necessary to remove all of the volatile solvent before nitrogen analysis. Thus all the solvent from CTD should be separated before sending it for analysis.

\subsubsection{DETERMINATION OF SOLVENT: CTD WEIGHT RATIO}

Each of the above solvents was mixed with coal tar distillate in different weight ratios and added to a $125 \mathrm{ml}$ flask. The flasks with different solutions were tightly closed with rubber stoppers wrapped with Para film and placed in the shaker bath at $30^{\circ} \mathrm{C}$ and $165 \mathrm{rpm}$ for $1 \mathrm{hr}$ as in the regular adsorption experimental procedure but this time without activated carbon. Then the solutions were filtered using vacuum flasks for the determination of undissolved CTD and the filtrates subjected to solvent evaporation in a heated water bath with gentle shaking at a temperature near the solvent's boiling point. 
It was observed that $\mathrm{CS}_{2}$ and THF at 4:1 solvent-to-CTD wt ratio performed better than toluene at 5:1 wt ratio. In these experiments, virtually all of the original weight of the starting CTD was recovered (shown in Table 3.2). Further experiments were then conducted with carbon disulfide and tetrahydrofuran at the $4: 1$ ratio to see which of these solvents performed better in the CTD treatment.

Table 3.2 Results of solubility test when $\mathrm{CS}_{2}$ is used as solvent

\begin{tabular}{|c|c|c|c|c|}
\hline $\begin{array}{c}\mathrm{CS}_{2} \text { to CTD } \\
\text { wt ratio }\end{array}$ & $\begin{array}{c}\text { Initial wt of } \\
\text { CTD }\end{array}$ & $\begin{array}{c}\text { Wt of CTD } \\
\text { recovered }\end{array}$ & $\% \mathrm{~N}$ initial & $\%$ N after \\
\hline $1: 1$ & 10.11 & 9.82 & 0.8925 & 0.8081 \\
\hline $2: 1$ & 10.15 & 10.10 & 0.8925 & 0.8363 \\
\hline $3: 1$ & 10.01 & 9.88 & 0.8925 & 0.8209 \\
\hline $4: 1$ & 10.03 & 9.84 & 0.8925 & 0.7819 \\
\hline $5: 1$ & 10.05 & 10.01 & 0.8925 & 0.8257 \\
\hline
\end{tabular}

\subsubsection{EXPERIMENTAL PROCEDURE}

A standard procedure was established for all the adsorption experiments in which activated carbon is used for the adsorption of nitrogen compounds from the coal tar distillate. A $50 \mathrm{~g}$ solution of $4: 1 \mathrm{wt}$ ratio of solvent to coal tar distillate is prepared by adding $40 \mathrm{~g}$ of solvent to $10 \mathrm{~g}$ of coal tar distillate. Activated carbon, Nuchar SA20, is added to the solution and mixed well. Prior to the addition, the carbon is vacuum heated at $300^{\circ} \mathrm{C}$ for $3 \mathrm{hrs}$ to remove moisture from its surface. Then the flask is tightly closed with a rubber stopper, sealed with parafilm and placed in the shaking water bath at $30^{\circ} \mathrm{C}$ as shown in Figure 3.3. After two hours of contact with carbon, the solution is carefully separated from the carbon through filtration. The walls of the flask and filter cake are washed with an extra $40 \mathrm{gm}$ of solvent to recover CTD trapped in the filter cake. Then 
the solvent is evaporated from solution in a water bath till constant weight is achieved (shown in Table 3.3).

Table 3.3 Data showing weight change of the CTD solution Vs time as solvent is evaporated

\begin{tabular}{|c|c|c|c|}
\hline Time, $\mathrm{hr}$ & wt, $\mathrm{g}$ & Time, $\mathrm{hr}$ & wt, $\mathrm{g}$ \\
\hline 0 & 44.01 & 3.5 & 13.84 \\
\hline 0.5 & 26.03 & 4.0 & 12.92 \\
\hline 1.0 & 25.56 & 4.5 & 12.33 \\
\hline 1.5 & 22.78 & 5.5 & 11.38 \\
\hline 2.0 & 19.68 & 6.0 & 11.12 \\
\hline 2.5 & 17.01 & 23.0 & 9.84 \\
\hline 3.0 & 15.05 & 24.00 & 9.84 \\
\hline
\end{tabular}

It is observed from previous experiments that when the solvent is evaporated from solution, the remaining CTD showed a reduction ( $\sim 5$ percent) in nitrogen content when compared to the raw CTD feed even without the addition of activated carbon. This reduction was accounted for in the calculation of percent nitrogen removed when the solution is treated with carbon. For this reason, a blank solution is processed exactly as per the established procedure but with no carbon in it and is analyzed for its nitrogen content along with a feed sample of CTD for comparison.

Using this standard procedure, experiments were conducted in two phases. In the first phase, Nuchar SA 20 activated carbon was used to determine the effect of the amount of activated carbon and time on the adsorption process. Then the Nuchar SA 20 is subjected to oxidation through different methods and the resultant oxidized carbon is tested for removal of the nitrogen species. In the second phase, similar experiments were conducted but with the WVUAC 900-15 activated carbon. 


\subsection{DEVELOPMENT OF SURFACE ACIDIC GROUPS}

From Song et al. [4] it is observed that activated carbons with more acidic surface groups adsorbed more sulfur compounds from diesel fuel than the carbons with little or no acidic surface functionality. Following that observation, the activated carbon was oxidized by different methods to introduce acidic groups to its surface. These carbons were in turn tested for nitrogen removal. Acidity of the oxidized carbon can be verified by the "pH test", described below.

The two methods used to oxidize both the activated carbons used in this research work are

a. Oxidation modification by nitric acid

b. Oxidation modification by air

In the first method, analytical-grade 68 percent nitric acid was used for oxidative modification of the activated carbon under mild conditions. The oxidation process was conducted by adding $100 \mathrm{ml}$ of the nitric acid to $10 \mathrm{~g}$ of the $\mathrm{AC}$ sample placed in a glass conical flask with a magnetic stirrer. The mixtures were kept at $30^{\circ} \mathrm{C}$ for 22 hours for one sample and 24 hours for another sample and then they were filtered to separate the carbon from the acid solution. The treated AC sample was further washed with distilled water until the filtrate became neutral. The filter cake was dried at $150^{\circ} \mathrm{C}$ in a vacuum oven for $1 \mathrm{hr}$ and then subjected to the analysis of surface $\mathrm{pH}$. 
For the oxidative modification by air, about $7 \mathrm{~g}$ of activated carbon sample was placed in a stainless steel pan as a thin layer. The sample was heated in an oven to $300^{\circ} \mathrm{C}$ in flowing air, and the sample was kept at this temperature under an air flow for $1 \mathrm{hr}$ and $3 \mathrm{hr}$. After the oxidation, the steel pan with sample was taken out and cooled in air. As before, the surface $\mathrm{pH}$ was determined.

\subsubsection{DETERMINATION OF SURFACE ACIDIC GROUPS}

The surface acidic groups were measured by means of the "pH-Test" as described by Song et al. [4]. Following the oxidation of the activated carbon, a sample of $0.5 \mathrm{~g}$ of the oxidized activated carbon was added to $25 \mathrm{ml}$ of water. The suspension was stirred for 24 hours to reach equilibrium. Then the activated carbon sample was filtered and the $\mathrm{pH}$ of the resulting solution was measured by means of a $\mathrm{pH}$ meter. While this is an indirect measure of the presence of acidic surface groups, the relative values allow comparison of the different oxidation treatments. The results of this test are shown in Table 4.6 in Chapter 4. 


\section{CHAPTER 4: RESULTS}

Experiments were carried out to determine the efficiency of as-received and oxidized Nuchar SA 20 with the surface area $1569 \mathrm{~m}^{2} / \mathrm{gm}$ and an average pore size $3 \mathrm{~nm}$ and WVUAC 900-15 activated carbon with the surface area $1400 \mathrm{~m}^{2} / \mathrm{gm}$ and an average pore size $2.7 \mathrm{~nm}$ for the removal of nitrogen species from coal tar distillate. The two selected solvents $\left(\mathrm{CS}_{2}\right.$ and THF) were each tested separately. Each time the experimental procedure described above in Section 3.3.3 was followed.

To test the solubility of CTD in $\mathrm{CS}_{2}$ and THF, blank runs were performed without the addition of the activated carbon. Koppers CTD was mixed with $\mathrm{CS}_{2}$ and THF solvents at 4:1 solvent to CTD wt ratio in two separate flasks. No activated carbon is used in this experiment. The flasks are placed in the water bath at $30^{\circ} \mathrm{C}$ for $2 \mathrm{hr}$ and then filtered. The obtained solutions were subjected to overnight treatment to evaporate solvent. When carbon disulfide was used as solvent, it was evaporated at $55^{\circ} \mathrm{C}$ while THF was evaporated at $75^{\circ} \mathrm{C}$. The CTD obtained after overnight treatment weighed and analyzed. From the results showed in Table 4.1, there is no difference in weight but the nitrogen content of the CTD after overnight treatment was changed slightly. A $10.16 \mathrm{~g}$ sample of undiluted CTD was also treated overnight at $55{ }^{\circ} \mathrm{C}$. It should be noted that when undiluted CTD was treated over night, no change in weight but a slight change in nitrogen content was detected (shown in Table 4.1). 
Table 4.1 Weight and nitrogen content of CTD during overnight treatment without the presence of activated carbon

\begin{tabular}{|c|c|c|c|c|c|c|}
\hline Solvent & $\begin{array}{c}\text { Solvent } \\
\text { to CTD } \\
\text { wt ratio }\end{array}$ & $\begin{array}{c}\text { Experimental } \\
\text { temperature, } \\
{ }^{\circ} \mathrm{C}\end{array}$ & $\begin{array}{c}\text { Initial } \\
\text { weight of } \\
\text { CTD, },\end{array}$ & $\begin{array}{c}\text { Weight of } \\
\text { CTD after } \\
\text { overnight } \\
\text { treatment, } \mathrm{g}\end{array}$ & $\begin{array}{c}\text { Initial \% } \\
\text { nitrogen } \\
\text { in CTD }\end{array}$ & $\begin{array}{c}\text { \% nitrogen } \\
\text { in CTD after } \\
\text { overnight } \\
\text { treatment }\end{array}$ \\
\hline- & - & 55 & 10.16 & 10.15 & 0.8585 & 0.8407 \\
\hline $\mathrm{CS}_{2}$ & $4: 1$ & 55 & 10.11 & 10.10 & 0.8585 & 0.8374 \\
\hline $\mathrm{THF}$ & $4: 1$ & 75 & 10.24 & 10.22 & 0.8585 & 0.8211 \\
\hline
\end{tabular}

\subsection{EFFECT OF SOLVENT AND AMOUNT OF NUCHAR SA 20}

\subsubsection{CARBON DISULFIDE AS SOLVENT}

The nitrogen species were removed from CTD by treating a 4:1 ratio of $\mathrm{CS}_{2}$ to CTD with different amounts of activated carbon at $30^{\circ} \mathrm{C}$ for $2 \mathrm{hrs}$ in a shaking water bath. Increasing amounts of carbon were tested at the same treatment time in different flasks to ascertain the effect of the amount of carbon on nitrogen removal. The experiment was repeated to test consistency of the results. From the results of the nitrogen analysis (Table 4.2 and 4.3), the percent of nitrogen removed from each sample was calculated and plotted against the amount of activated carbon used for $\mathrm{CS}_{2}$ (Figure 4.1). The percentage of nitrogen in the treated CTD along with the nitrogen in the carbon after adsorption was determined so that a nitrogen balance could be performed (Table 4.4).

As can be seen in Figure 4.1, the percentage of nitrogen removed has a strong correlation with the amount of carbon contacted with the CTD. The results from the first run experiment show that over 90 percent of the nitrogen-containing species were removed from the CTD. This results in a treated CTD with a nitrogen content of less than 0.1 percent. This is significantly less than the original nitrogen content of $1.11 \%$ by 
weight. Even though there is no change in the experimental procedure, $20.5 \%$ experimental error in terms of percent nitrogen removal is observed between first and second runs. The reason for the error is not understood.

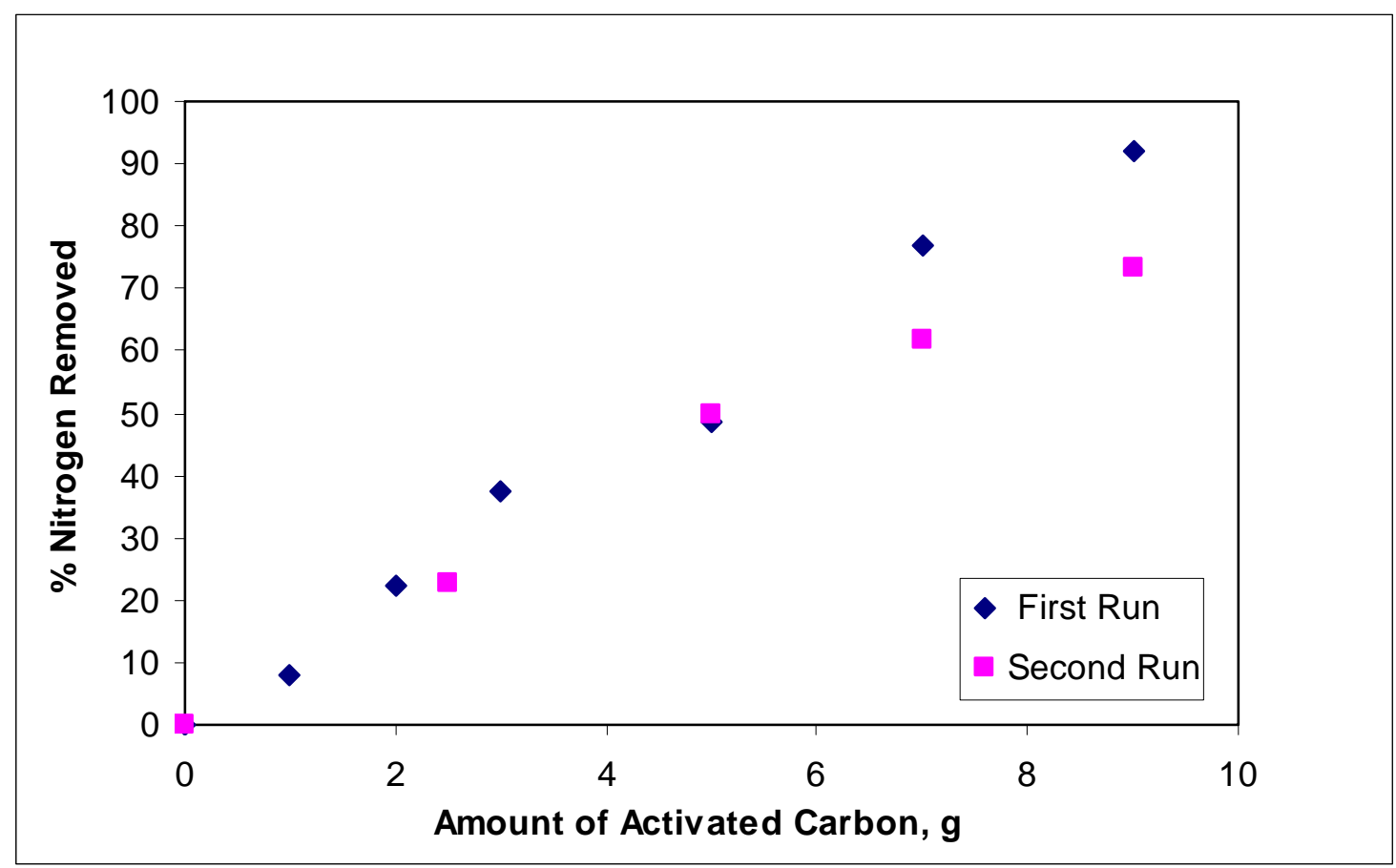

Figure 4.1 Plot of percent nitrogen removed Vs. amount of Nuchar activated carbon with $\mathrm{CS}_{2}$ as the solvent at $30^{\circ} \mathrm{C}$.

From the nitrogen analysis results, it is observed that the starting nitrogen content of CTD is different for both the runs. For the first run, the starting nitrogen content was $1.02 \mathrm{wt} \%$ while for the second run it was $0.61 \mathrm{wt} \%$. This clearly indicates that the CTD sample was different in both cases and no doubt contained varying nitrogen functionalities. This points out the need for careful sampling of the CTD. While every attempt was made to attain a consistent sample, apparently it is more difficult than expected. This could be a possible reason for the difference between the results of the two runs. 
Table 4.2 Nitrogen content and yield of CTD when 4:1 CS $\mathrm{CS}_{2}$ CTD solution was treated with Nuchar SA 20 in the first run

\begin{tabular}{|c|c|c|c|c|c|}
\hline $\begin{array}{c}\text { Amount of } \\
\text { activated } \\
\begin{array}{c}\text { Carbon } \\
\mathrm{g}\end{array}\end{array}$ & $\begin{array}{c}\text { Nitrogen in } \\
\text { treated CTD } \\
\text { wt } \%\end{array}$ & $\begin{array}{c}\text { Nitrogen } \\
\text { Removed } \\
\%\end{array}$ & $\begin{array}{c}\text { Initial } \\
\text { CTD } \\
\mathrm{g}\end{array}$ & $\begin{array}{c}\text { CTD wt } \\
\text { loss, } \\
\mathrm{g}\end{array}$ & $\begin{array}{c}\text { Yield of } \\
\text { CTD } \\
\text { wt } \%\end{array}$ \\
\hline Feed & 0.9455 & - & - & - & - \\
\hline 0 & 1.0160 & 0 & 10.15 & 0.26 & 97.438 \\
\hline 1 & 0.7732 & 7.81 & 10.06 & 0.1 & 99.006 \\
\hline 2 & 0.7928 & 22.32 & 10.23 & 0.53 & 94.819 \\
\hline 3 & 0.6529 & 37.33 & 10.54 & 0.81 & 92.315 \\
\hline 5 & 0.5391 & 48.54 & 10.03 & 1.34 & 88.335 \\
\hline 7 & 0.1575 & 76.74 & 10.48 & 1.42 & 81.584 \\
\hline 9 & 0.0509 & 92.00 & 10.18 & 2.57 & 72.986 \\
\hline
\end{tabular}

After treatment, the weight of the recovered CTD was measured. It was found that the weight of the recovered CTD was less than the weight of the CTD in the flask before treatment. The reduced weight of the treated CTD is due to the removal of the molecules containing nitrogen through adsorption. The yield of the treated CTD for both the runs was given in Tables 4.2 and 4.3. It is also observed that the yield of the treated CTD decreases with increasing amount of activated carbon and increasing removal of nitrogen.

Table 4.3 Nitrogen content and yield of CTD when 4:1 $\mathrm{CS}_{2}$ : CTD solution was treated with Nuchar SA 20 in the second run

\begin{tabular}{|c|c|c|c|c|c|}
\hline $\begin{array}{c}\text { Amount of } \\
\text { activated } \\
\begin{array}{c}\text { Carbon } \\
\mathrm{g}\end{array}\end{array}$ & $\begin{array}{c}\text { Nitrogen in } \\
\text { treated CTD } \\
\text { wt \% }\end{array}$ & $\begin{array}{c}\text { Nitrogen } \\
\text { Removed } \\
\%\end{array}$ & $\begin{array}{c}\text { Initial } \\
\text { CTD } \\
\mathrm{g}\end{array}$ & $\begin{array}{c}\text { CTD wt } \\
\text { loss, } \\
\mathrm{g}\end{array}$ & $\begin{array}{c}\text { Yield of } \\
\text { CTD } \\
\text { wt \% }\end{array}$ \\
\hline Feed & 0.7390 & - & - & - & - \\
\hline 0 & 0.6083 & 0 & 10.06 & 0.15 & 98.509 \\
\hline 2.5 & 0.4698 & 22.76 & 10.22 & 0.67 & 93.444 \\
\hline 5 & 0.3046 & 49.92 & 10.19 & 1.17 & 88.518 \\
\hline 7 & 0.2324 & 61.79 & 10.13 & 1.80 & 82.231 \\
\hline 9 & 0.1634 & 73.13 & 10.33 & 2.21 & 78.606 \\
\hline
\end{tabular}




\subsubsection{NITROGEN BALANCE}

The nitrogen content of the activated carbon was measured before and after treatment. Before the treatment of CTD there was no nitrogen content in the activated carbon. After treatment, nitrogen was detected in the activated carbon. Nitrogen balance was performed to ascertain whether the nitrogen loss in the treated CTD was equal to the increased nitrogen content in the spent activated carbon. To calculate the amount of nitrogen in the starting CTD, treated CTD and the spent activated carbon Equations 1-3 (shown below) was used.

1. Nitrogen in the starting CTD, $g=$ Wt. of the starting CTD $* \frac{\% \mathrm{~N} \text { in the starting CTD }}{100}$

2. Nitrogen in the treated CTD, $g=$ Wt. of the treated CTD $* \frac{\% \mathrm{~N} \text { in the treated CTD }}{100}$

3. Nitrogen in the spent activated carbon, $\mathrm{g}=$

(Wt. of the activated carbon $+\mathrm{Wt}$. loss of CTD) $* \frac{\% \mathrm{~N} \text { in the spent activated carbon }}{100}$

Nitrogen balance was performed by subtracting nitrogen in the treated CTD and nitrogen in the spent activated carbon from nitrogen in the starting CTD.

The results of the nitrogen balance in Table 4.4 and 4.5 shows that despite the many operations in processing and the small amounts of nitrogen in the samples, the nitrogen balance closes to a high of $16.9 \%$ and a low of $1.1 \%$ for an average closure of 8 $.08 \%$. This gives some confidence that the procedure is working and the analytical procedure is consistent. The difference in the nitrogen balance might be from slight differences in the experimental procedure. 
Table 4.4 Nitrogen distribution between CTD solution and Nuchar SA 20 activated carbon for first run

\begin{tabular}{|c|c|c|c|c|c|}
\hline $\begin{array}{c}\text { Carbon, } \\
\mathrm{g}\end{array}$ & $\begin{array}{c}\text { Nitrogen in } \\
\text { the starting } \\
\text { CTD, g }\end{array}$ & $\begin{array}{c}\text { Nitrogen in } \\
\text { the treated } \\
\text { CTD, } \mathrm{g}\end{array}$ & $\begin{array}{c}\text { Nitrogen } \\
\text { in the spent } \\
\text { activated } \\
\text { carbon, } \mathrm{g}\end{array}$ & $\begin{array}{c}\text { Difference, } \\
\mathrm{g}\end{array}$ & $\begin{array}{c}\text { Difference } \\
\%\end{array}$ \\
\hline 0 & 0.1016 & 0.1016 & 0 & 0 & 0 \\
\hline 1 & 0.0865 & 0.0765 & 0.0062 & 0.0038 & 4.3931 \\
\hline 2 & 0.1039 & 0.0769 & 0.0094 & 0.0176 & 16.939 \\
\hline 3 & 0.1070 & 0.0635 & 0.0423 & 0.0012 & 1.1215 \\
\hline 5 & 0.1036 & 0.0477 & 0.0422 & 0.0137 & 13.2239 \\
\hline 7 & 0.0677 & 0.0135 & 0.0510 & 0.0032 & 4.7267 \\
\hline 9 & 0.0677 & 0.0037 & 0.0640 & 0 & 0 \\
\hline
\end{tabular}

Table 4.5 Nitrogen distribution between CTD solution and Nuchar SA 20 activated carbon for second run

\begin{tabular}{|c|c|c|c|c|c|}
\hline $\begin{array}{c}\text { Carbon, } \\
\mathrm{g}\end{array}$ & $\begin{array}{c}\text { Nitrogen in } \\
\text { the starting } \\
\text { CTD, g }\end{array}$ & $\begin{array}{c}\text { Nitrogen in } \\
\text { the treated } \\
\text { CTD, } \mathrm{g}\end{array}$ & $\begin{array}{c}\text { Nitrogen } \\
\text { in the spent } \\
\text { activated } \\
\text { carbon, } \mathrm{g}\end{array}$ & $\begin{array}{c}\text { Difference, } \\
\mathrm{g}\end{array}$ & $\begin{array}{c}\text { Difference } \\
\%\end{array}$ \\
\hline 0 & 0.0614 & 0.0614 & - & - & - \\
\hline 2.5 & 0.0622 & 0.0449 & 0.0194 & 0.0015 & 2.33 \\
\hline 5 & 0.0613 & 0.0276 & 0.0337 & 0 & 0 \\
\hline 7 & 0.0631 & 0.0194 & 0.0435 & 0.0002 & 0.31 \\
\hline 9 & 0.0650 & 0.0133 & 0.0478 & 0.0039 & 6.00 \\
\hline
\end{tabular}

\subsubsection{TESTING TETRAHYDROFURAN AS SOLVENT}

Figure 4.2 shows the results of the experiment following the same procedure as above except this time THF is used as the solvent in a 4:1 solvent-to-CTD wt ratio and reacted with Nuchar SA20 at $30^{\circ} \mathrm{C}$ for $2 \mathrm{hrs}$ in the shaker bath. The starting nitrogen content of the CTD is $0.8884 \mathrm{wt} \%$. It can be seen that for similar ratios of CTD and activated carbon, the treatment with THF results in a much lower percentage of nitrogen 
removal when compared to the $\mathrm{CS}_{2}$. Thus for all the subsequent runs, $\mathrm{CS}_{2}$ is used as the preferred solvent at a 4:1 solvent-to-CTD ratio.

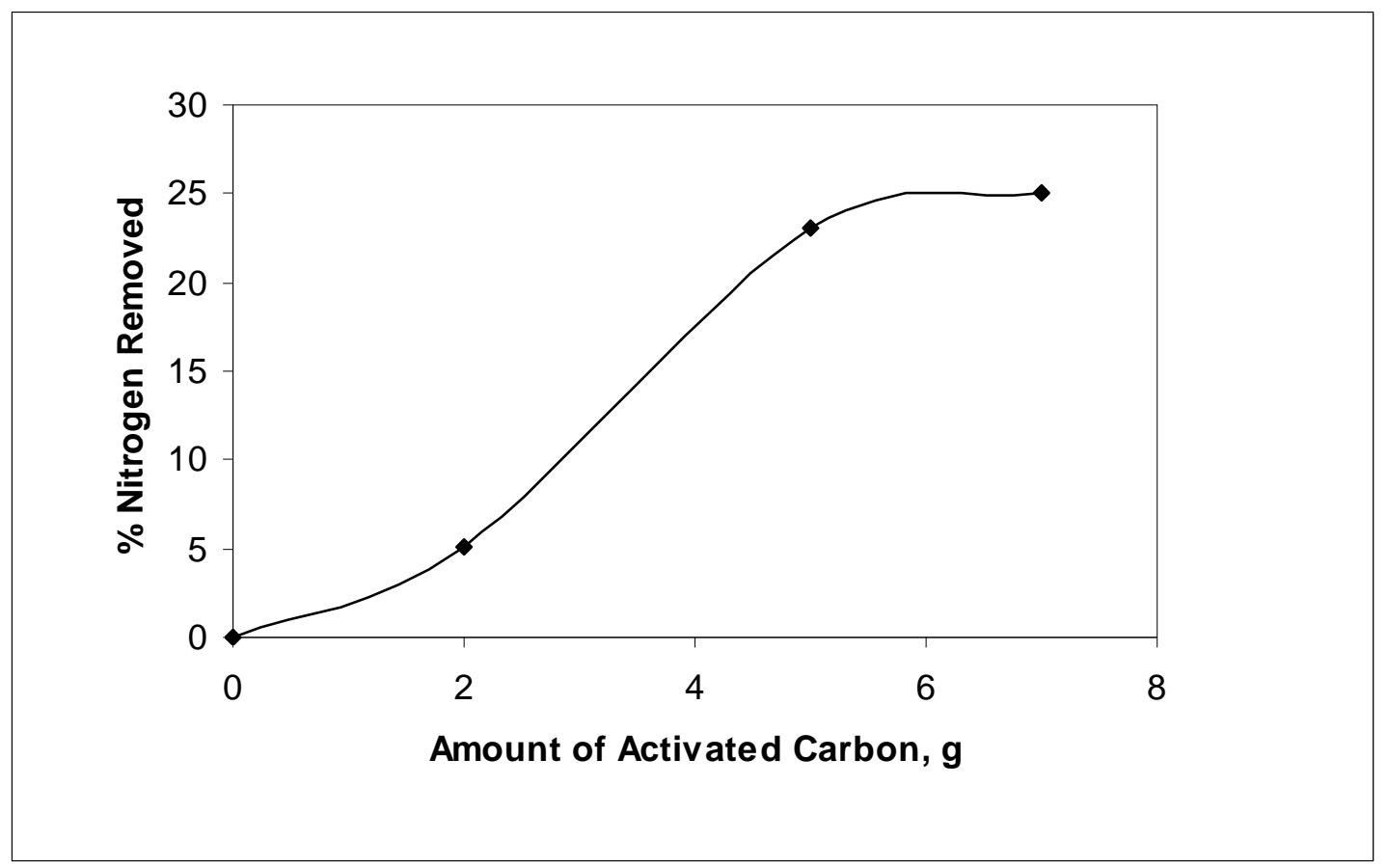

Figure.4.2 Testing THF as a solvent with increasing amounts of Nuchar SA20 for 2 hrs at $30^{\circ} \mathrm{C}$

\subsection{TWO STEP ADSORPTION PROCESS}

A two-stage adsorption procedure was attempted in which CTD samples that were treated with 4 and 7 grams of activated carbon in the first step and were retreated with 5 grams of fresh activated carbon in the second step. In both the steps, Nuchar SA 20 in different amounts is added to a 4:1 $\mathrm{CS}_{2}$ to $\mathrm{CTD}$ wt ratio solution and reacted in shaker bath at $30^{\circ} \mathrm{C}$ for $2 \mathrm{hrs}$. The nitrogen concentration in feed is 0.8004 and the total percentage of nitrogen removed in the two-step process was 79 percent and 92 percent respectively. A one step process was performed with $9 \mathrm{~g}$ of carbon to compare the effectiveness with the two-stage process (as shown in Figure 4.3). Thus, it appears that 
one step using 9 grams of carbon is as good as two steps which use a total of 9 and 12 grams of carbon.

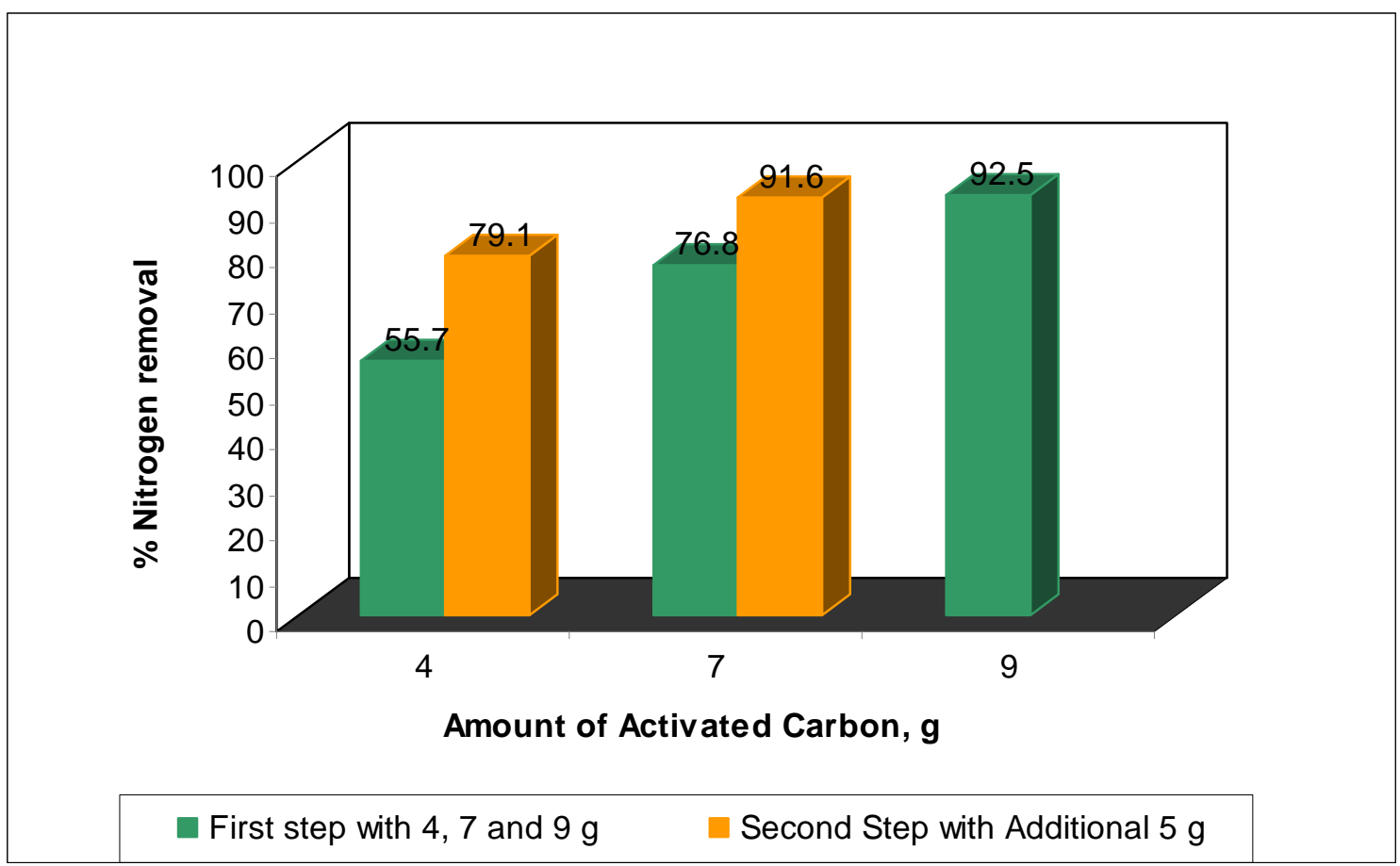

Figure 4.3 Effect of Two-Step Adsorption Process compared to a one-step process

\subsection{EFFECT OF CONTACT TIME ON NITROGEN REMOVAL}

To assess the effect of contact time between the activated carbon and the CTD, an experiment was conducted by keeping the amount of activated carbon constant at $5 \mathrm{~g}$ and varying the contact time. The initial nitrogen content of the CTD was 0.9476 . Five 125 $\mathrm{ml}$ flasks were filled with a 4:1 wt ratio solution of $\mathrm{CS}_{2}$ and CTD and $5 \mathrm{~g}$ Nuchar SA 20 is added to each flask. Then they were placed in a shaker bath which was maintained at $30^{\circ} \mathrm{C}$. The contents of each flask were collected at different times of $1,2.5,4,5$ and $6 \mathrm{hr}$ respectively and the activated carbon was removed from solution by vacuum filtration. Then $\mathrm{CS}_{2}$ was evaporated from the collected samples and the remaining CTD was sent 
for nitrogen analysis. Figure 4.4 shows the percent nitrogen removed over a period of 6 hrs. From the plot it is observed that the majority of the adsorption reaction is taking place with in the first hour. No appreciable nitrogen removal is observed during the remaining time.

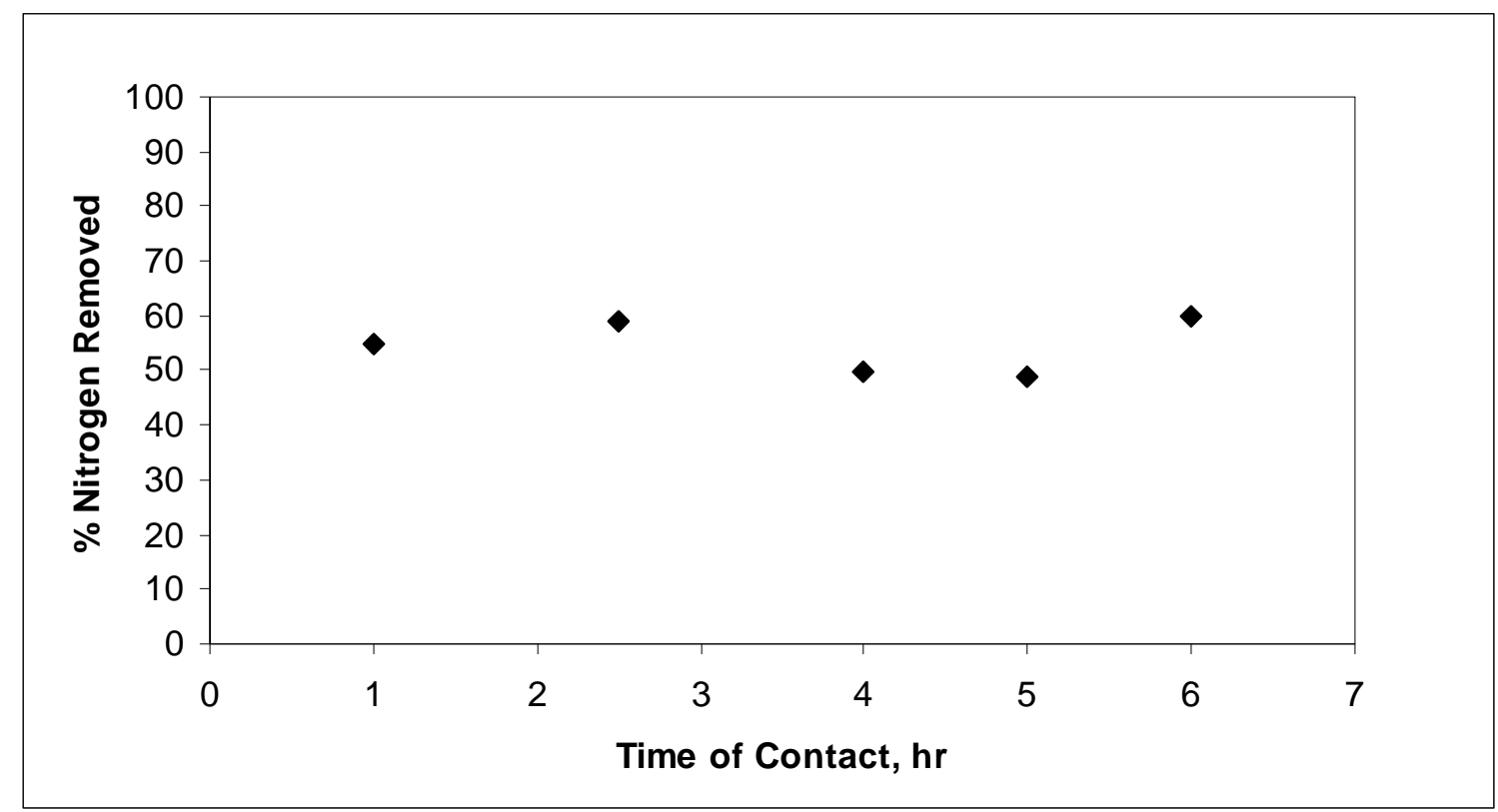

Figure 4.4 Effect of contact time on percent nitrogen removal when $5 \mathrm{~g}$ of air oxidized Nuchar SA20 is contacted with solution of $\mathrm{CS}_{2}$ and CTD at 4:1 wt ratio.

\subsection{EFFECT OF OXIDATION}

The Nuchar activated carbon is subjected to oxidation with air and nitric acid, each acting as oxidizing agents (see Section 3.4). It is believed that oxidation improves the acidic functional groups on the surface of activated carbon. This can be observed through a $\mathrm{pH}$ test. The decrease in the $\mathrm{pH}$ of the oxidized activated carbon shows an increase in the number of acidic surface functional groups. The results of the $\mathrm{pH}$ test of various oxidized carbons are given in Table 4.6. From the data in Table 4.6 it is clear that the Nuchar carbon oxidized for $24 \mathrm{~h}$ with nitric acid has the lowest $\mathrm{pH}$. 
Table 4.6 pH of unoxidized and oxidized carbons

\begin{tabular}{|c|l|c|c|}
\hline & \multicolumn{1}{|c|}{ Sample } & $\mathrm{pH}$ & \% Nitrogen Removed \\
\hline 1 & Unoxidized Nuchar SA 20 & 5.8 & 47.22 \\
\hline 2 & 1 hr air oxidized Nuchar SA 20 & 4.1 & 57.58 \\
\hline 3 & 3 hr air oxidized Nuchar SA 20 & 3.4 & 52.94 \\
\hline 4 & $\begin{array}{l}\text { Nuchar SA 20 oxidized with nitric } \\
\text { acid for 22 hrs }\end{array}$ & 3.3 & 56.08 \\
\hline 5 & $\begin{array}{l}\text { Nuchar SA 20 oxidized with nitric } \\
\text { acid for 24 hrs }\end{array}$ & 3.1 & 64.60 \\
\hline
\end{tabular}

The above oxidized carbons were tested for adsorption of nitrogen compounds from the CTD as per the experimental procedure described above with 5 grams of carbon at $30^{\circ} \mathrm{C}$ for $2 \mathrm{hrs}$. The nitrogen content of the feed CTD is $1.003 \mathrm{wt}$ percent. The activated carbon oxidized with nitric acid for $24 \mathrm{hrs}$ had the lowest surface $\mathrm{pH}$ and showed better nitrogen removal than the other oxidized as well as the unoxidized carbons for the same carbon-to-CTD ratio (see Figure 4.5). Here carbon disulfide was used as the solvent.

While the improvement in nitrogen removal with the oxidized carbons is not great $(\sim 30 \%)$ these results indicate that, as expected, the surface functionality of carbon does play a role in the nitrogen adsorption. Since percent nitrogen removal with air oxidized carbon is as good as that of with nitric acid oxidized carbons, air oxidation appears to be a promising treatment since it requires a much shorter oxidation time and a much simpler reaction scheme. 


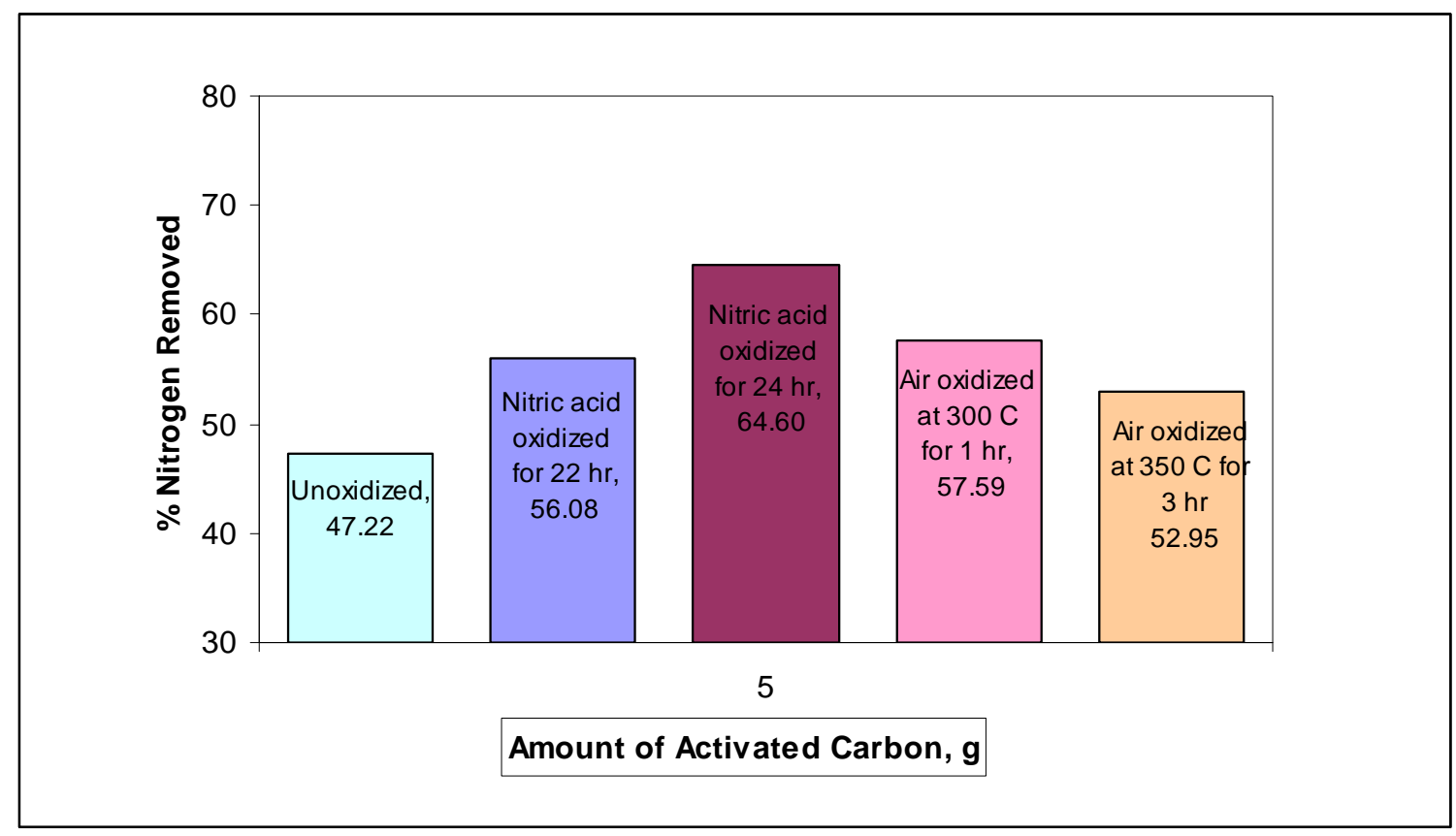

Figure 4.5 Effect of oxidized carbons on nitrogen removal

The activated carbon was vacuum heated to remove any moisture present in it before adding it to the CTD. This step is important as it enhances the performance of the activated carbon. The unoxidized carbon was vacuum heated at $300^{\circ} \mathrm{C}$ for $3 \mathrm{hrs}$. But the oxidized carbons have some newly added surface functional groups through the oxidation step and the strength of the bonds through which these functional groups are attached to the surface of the activated carbon is unknown. If they are weakly bonded, there is a chance that vacuum treatment of the activated carbon may remove these acidic functional groups.

\subsection{EFFECT OF VACUUM TREATMENT}

In an experiment to determine the effect of vacuum treatment on the performance of activated carbon, four different samples of Nuchar SA 20 were prepared: 1) Air oxidized (at $300 \mathrm{C}$ for $1 \mathrm{hr}$ ) and vacuum treated at $300^{\circ} \mathrm{C}$ for $2 \mathrm{hr}, 2$ ) Air oxidized (at 300 
$\mathrm{C}$ for $1 \mathrm{hr}$ ) and vacuum treated at $100^{\circ} \mathrm{C}$ for $\left.2 \mathrm{hr}, 3\right)$ Unoxidized Nuchar carbon vacuum treated at $100^{\circ} \mathrm{C}$ for $\left.3 \mathrm{hr}, 4\right)$ Unoxidized activated carbon with no vacuum treatment. Micromeritics VacPrep 061 unit was used for degassing the activated carbon. The vacuum treated carbons were tested to remove nitrogen species from CTD following the standard experiment procedure. Each of the four activated carbon samples mentioned

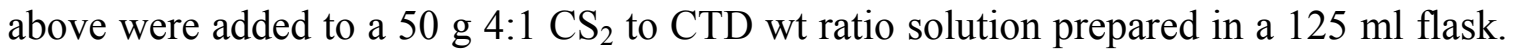
Amount of activated carbon added is kept constant at $5 \mathrm{~g}$. The four flasks along with the feed and control (with no activated carbon) were placed in shaking water bath at $30 \mathrm{C}$ for $2 \mathrm{hrs}$. Then the activated carbon was separated from solution through vacuum filtration and the solvent was evaporated from the solution through overnight treatment. The denitrogenated CTD was analyzed and the results are shown in Figure 4.6.

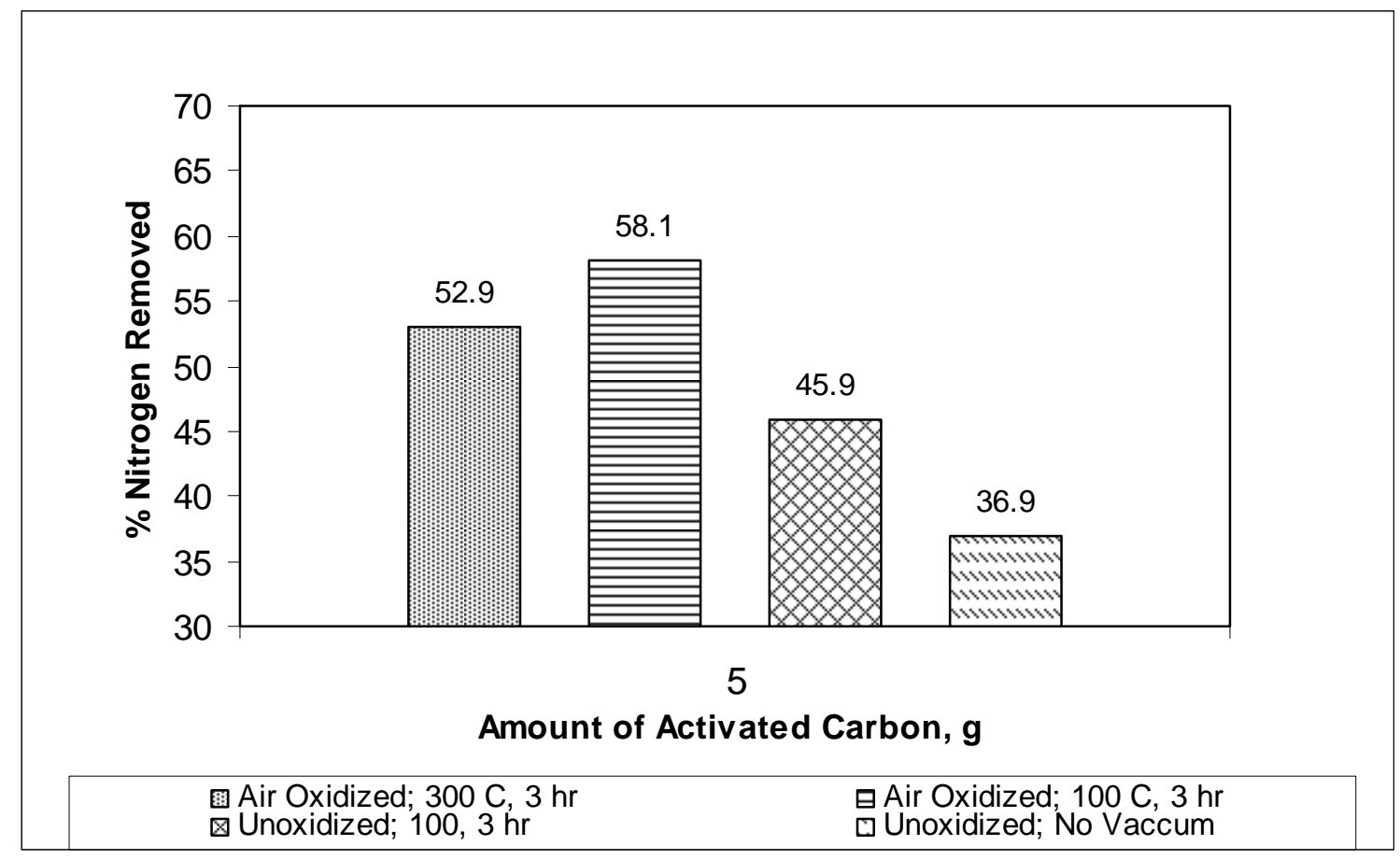

Figure 4.6 Effect of vacuum treatment of activated carbon on nitrogen removal 
It is observed that the air oxidized activated carbon which is vacuum treated at $100^{\circ} \mathrm{C}$ for 3 hrs showed better nitrogen removal than that of vacuum treated at $300^{\circ} \mathrm{C}$. This suggests that over-heating of the oxidized activated carbon may remove some surface functional groups which reduces its capacity to adsorb nitrogen species. Thus for all further experiments activated carbon is vacuum heated at $100^{\circ} \mathrm{C}$ for $3 \mathrm{hr}$ before adding it to the CTD.

\subsection{EFFECT OF WVUAC 900-15 ACTIVATED CARBON}

In the second phase of the experiments, WVUAC 900-15 activated carbon with a surface area $1400 \mathrm{~m}^{2} / \mathrm{g}$ and an average pore size $2.7 \mathrm{~nm}$ is used to determine the effects of amount of carbon (Figure 4.7) and time (Figure 4.8) on the extent of nitrogen removal. Later the WVU activated carbon was oxidized using air and nitric acid as oxidizing agents and the resulted carbon was tested for its efficiency in removing nitrogen species from Koppers CTD (Figure 4.9).

Increasing amounts; 3, 5, 7 and $9 \mathrm{~g}$ of WVUAC 900-15 were added to the CTD solution in four different flasks and treated in shaking water bath at $30^{\circ} \mathrm{C}$. The nitrogen concentration of feed CTD is $1.001 \mathrm{wt} \%$. The results of the increased amounts of WVU activated carbon on the amount of $\mathrm{N}$ removal are shown in Figure 4.7. Percent nitrogen removed increases with increase in amount of activated carbon. It is found that only $20 \%$ nitrogen was removed with 9 gm of WVUAC 900-15 carbon, while with Nuchar carbon about $90 \%$ nitrogen was removed from CTD. 


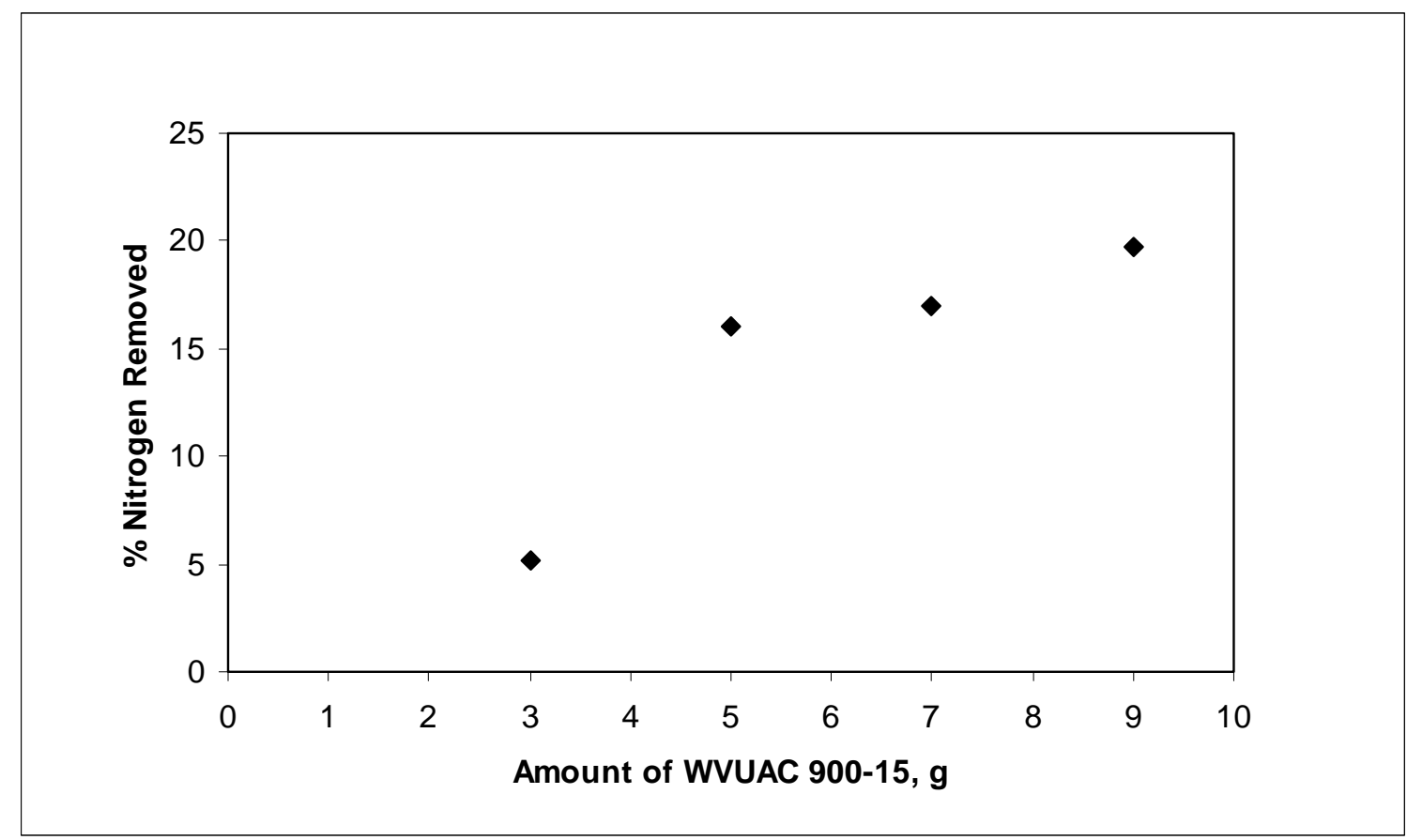

Figure 4.7 Effect of increasing amounts of WVUAC900-15 when $\mathrm{CS}_{2}$ is used as solvent

To determine the effect of contact time on adsorption process, WVU activated carbon was contacted with a 4:1 $\mathrm{CS}_{2}$ to $\mathrm{CTD}$ wt ratio solution for 1, 2, 4 and $6 \mathrm{hrs}$ in four different flaks at $30^{\circ} \mathrm{C}$. Later the activated carbon was separated from the solution and solvent was evaporated. From the nitrogen analysis results of the remaining CTD, percent nitrogen removed was calculated and plotted against contact time. The plot is shown in Figure 4.8. It is found that most of the adsorption reaction is taking place with in an hour. This observation is consistent with that seen for the Nuchar activated carbon under similar conditions. 


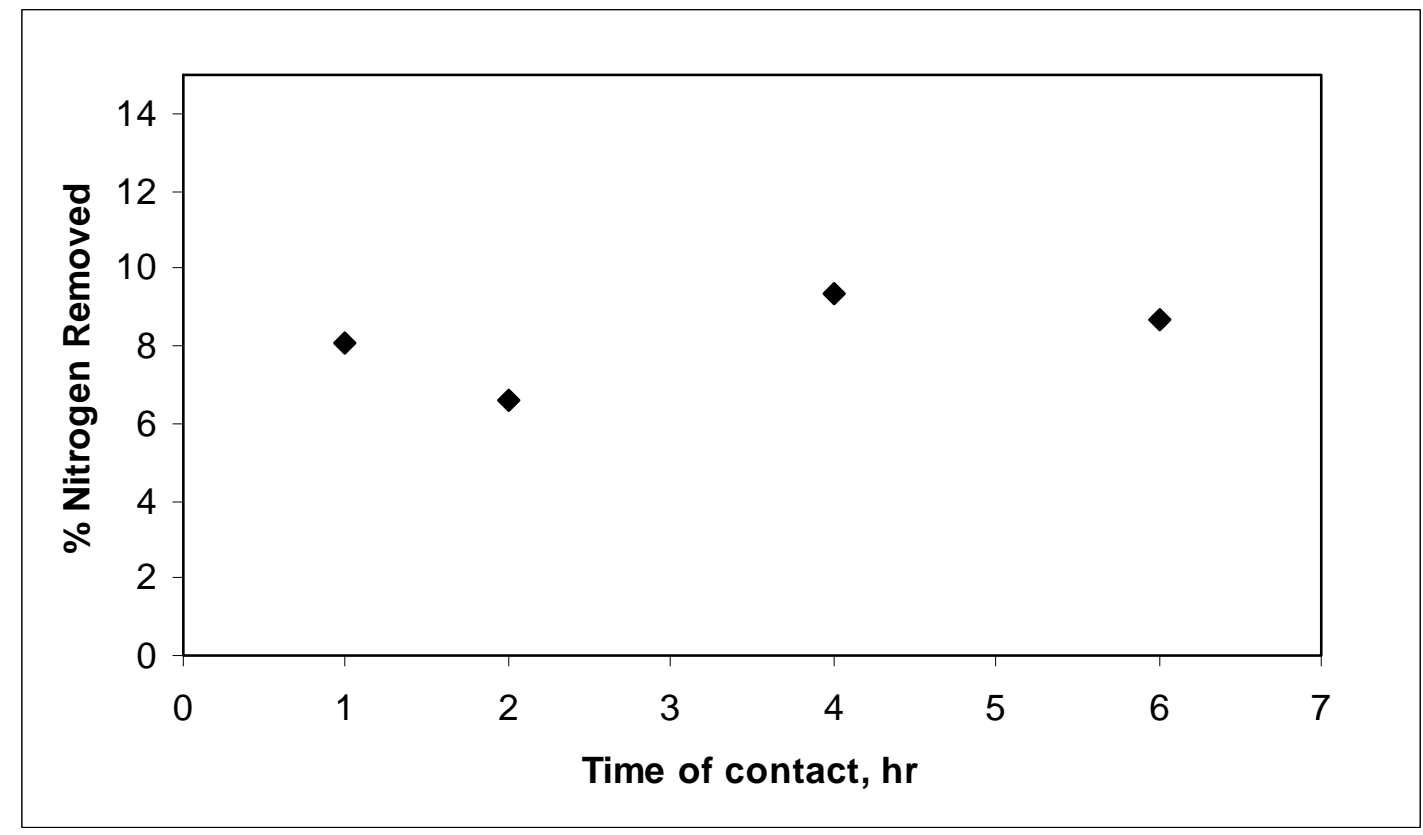

Figure 4.8 Percent nitrogen removed plotted against contact time between $5 \mathrm{~g}$ of WVUAC 900-15 and 4:1 wt ratio solution of $\mathrm{CS}_{2}$ and CTD

Finally the surface functional groups of the WVU activated carbon were modified via oxidation with air and nitric acid at $300^{\circ} \mathrm{C}$ for $1 \mathrm{hr}$ and at $25^{\circ} \mathrm{C}$ for $24 \mathrm{hrs}$ respectively. These two oxidized WVU carbons along with unoxidized WVUAC900-15 were tested to remove nitrogen species from Koppers CTD following the established procedure and with $\mathrm{CS}_{2}$ as the solvent. The results are shown in Figure 4.9. Air oxidized WVU activated carbon was able to remove more nitrogen species than the unoxidized and nitric acid oxidized carbons. 


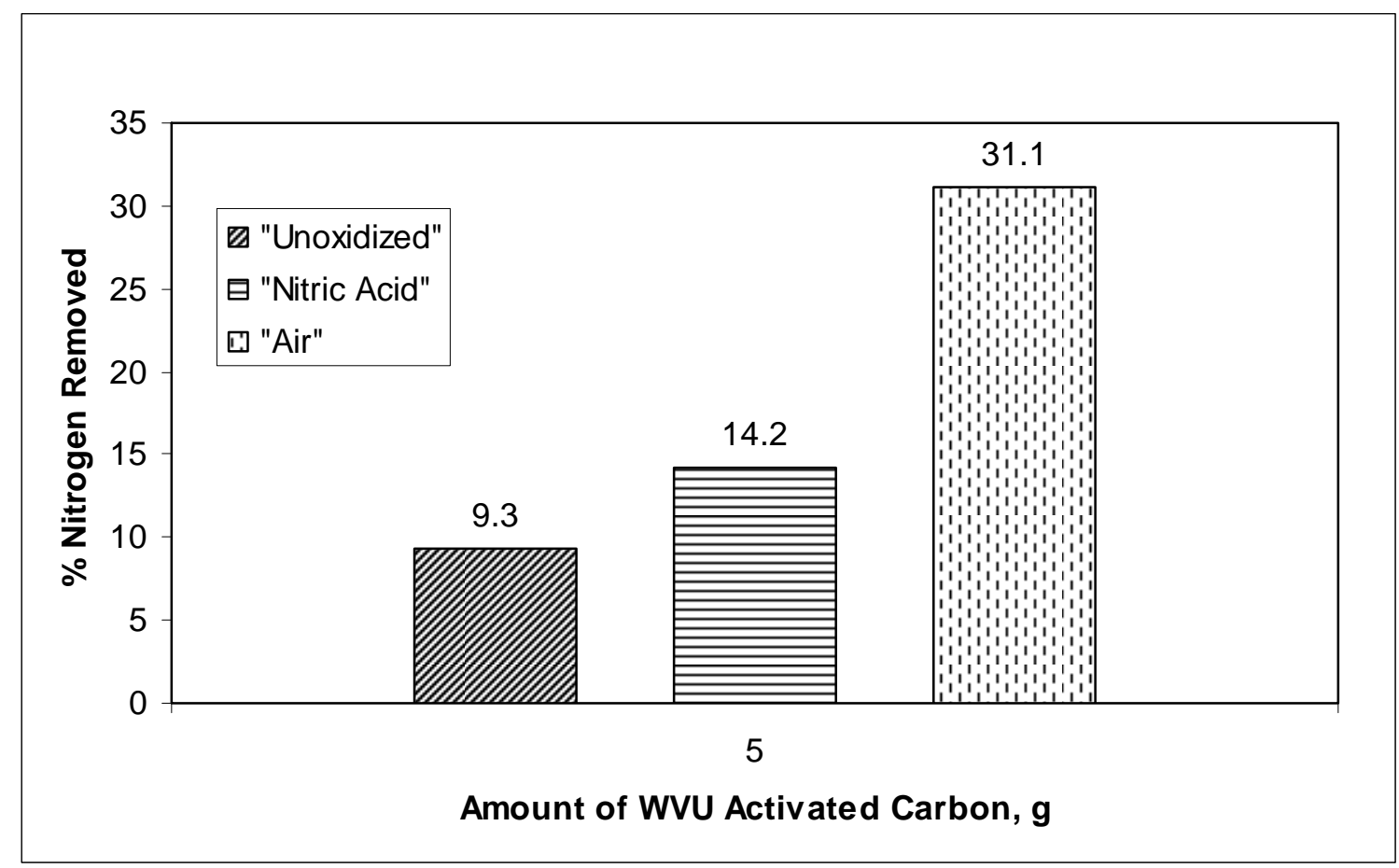

Figure 4.9 Plot showing percent nitrogen removed with unoxidized, nitric acid oxidized and air oxidized WVUAC 900-15 activated carbon

\subsection{LARGE BATCH OF TREATED CTD}

A 400g sample of treated CTD was prepared and sent to GrafTech International Ltd for conversion in to graphite. The large sample of treated CTD was prepared by combing several smaller samples of treated CTD. A sample consisted of a $50 \mathrm{~g}$ mixture of $\mathrm{CS}_{2}$ and CTD at a 4:1 wt ratio treated with $7 \mathrm{~g}$ of air oxidized Nuchar SA 20 in a shaker bath at $30^{\circ} \mathrm{C}$ for $2 \mathrm{hr}$. The Nuchar activated carbon was pretreated by oxidizing it in air at $300^{\circ} \mathrm{C}$ for $1 \mathrm{hr}$. After treatment the activated carbon was separated from solution by vacuum filtration and the solvent was evaporated at $55^{\circ} \mathrm{C}$. Six identical samples were treated simultaneously during a single run. With each run, undiluted CTD as feed and CTD mixed with $\mathrm{CS}_{2}$ at $4: 1$ solvent to $\mathrm{CTD}$ wt ratio were also included to calculate $\% \mathrm{~N}$ 
removed. The $400 \mathrm{~g}$ batch was accumulated from 9 runs. The nitrogen content of the feed CTD and the nitrogen analysis results of the treated CTD for 9 runs are given in Table 4.7 .

Each time when analyzing the nitrogen content, the CTD sample was analyzed four times and the average of the best three analysis results was reported as the nitrogen content of the CTD sample. The elemental analyzer report also includes the standard deviation, the percent relative standard deviation and variance between the best three analysis results of the CTD sample. The average standard deviation and the average relative standard deviation for all the treated CTD samples from 9 runs are 0.0241 and $4.0244 \%$ respectively. The standard deviation is very small showing that the reported nitrogen content of CTD is consistent and precise.

Table 4.7 Results of de-nitrogenation of CTD

\begin{tabular}{|c|c|c|c|c|c|c|}
\hline & \multicolumn{2}{|c|}{ Run 1 } & \multicolumn{2}{c|}{ Run 2 } & \multicolumn{2}{c|}{ Run 3 } \\
\hline Material & $\begin{array}{c}\text { Nitrogen } \\
\text { content } \\
(\mathrm{wt} \%)\end{array}$ & $\begin{array}{c}\mathbf{1}^{1} \text { Nitrogen } \\
\text { Removed, } \\
(\%)\end{array}$ & $\begin{array}{c}\text { Nitrogen } \\
\text { content } \\
(\mathrm{wt} \%)\end{array}$ & $\begin{array}{c}\text { Nitrogen } \\
\text { Removed, } \\
(\%)\end{array}$ & $\begin{array}{c}\text { Nitrogen } \\
\text { content } \\
(\mathrm{wt} \%)\end{array}$ & $\begin{array}{c}\text { Nitrogen } \\
\text { Removed, } \\
(\%)\end{array}$ \\
\hline Feed & 0.9794 & - & 0.9156 & - & 0.9898 & - \\
\hline${ }^{2}$ CTD+ CS 2 & 0.9817 & - & 0.9059 & - & 0.9699 & - \\
\hline${ }^{3}$ Treated & 0.5456 & 44.4229 & 0.6670 & 26.3716 & 0.6138 & 36.7151 \\
\hline Treated & 0.6394 & 34.8681 & 0.6451 & 28.7890 & 0.6580 & 32.1580 \\
\hline Treated & 0.6246 & 36.3757 & 0.6438 & 28.9326 & 0.6112 & 36.9832 \\
\hline Treated & 0.6244 & 36.3960 & 0.6436 & 28.9546 & 0.6876 & 29.1061 \\
\hline Treated & 0.6363 & 35.1839 & 0.6153 & 32.0786 & 0.6666 & 31.2713 \\
\hline Treated & 0.6357 & 35.2450 & 0.6639 & 26.7138 & 0.5661 & 41.6332 \\
\hline Treated & 0.7064 & 28.0432 & 0.6339 & 30.0254 & - & - \\
\hline
\end{tabular}


Table 4.7 Results of de-nitrogenation of CTD (Continued)

\begin{tabular}{|c|c|c|c|c|c|c|}
\hline & \multicolumn{2}{|c|}{ Run 4 } & \multicolumn{2}{c|}{ Run 5 } & \multicolumn{2}{c|}{ Run 6 } \\
\hline Material & $\begin{array}{c}\text { Nitrogen } \\
\text { content } \\
(\mathrm{wt} \%)\end{array}$ & $\begin{array}{c}\text { Nitrogen } \\
\text { Removed, } \\
(\%)\end{array}$ & $\begin{array}{c}\text { Nitrogen } \\
\text { content } \\
(\mathrm{wt} \%)\end{array}$ & $\begin{array}{c}\text { Nitrogen } \\
\text { Removed, } \\
(\%)\end{array}$ & $\begin{array}{c}\text { Nitrogen } \\
\text { content } \\
(\mathrm{wt} \%)\end{array}$ & $\begin{array}{c}\text { Nitrogen } \\
\text { Removed, } \\
(\%)\end{array}$ \\
\hline Feed & 0.8094 & - & 0.8789 & - & 0.7859 & - \\
\hline CTD+ CS ${ }_{2}$ & - & - & 0.7635 & - & 0.7457 & - \\
\hline Treated & 0.5340 & 34.0277 & 0.5460 & 28.4872 & 0.5413 & 27.4105 \\
\hline Treated & 0.5135 & 36.5579 & 0.5482 & & 0.5616 & 24.6882 \\
\hline Treated & 0.5382 & 33.5063 & 0.5358 & 29.8232 & 0.5391 & 27.7055 \\
\hline Treated & 0.5282 & 34.7418 & 0.5436 & 28.8016 & 0.5447 & 26.9545 \\
\hline Treated & 0.5332 & 34.1240 & 0.5201 & 31.8795 & 0.5189 & 30.4144 \\
\hline Treated & 0.5248 & 35.1618 & 0.5315 & 30.3864 & 0.4861 & 34.8129 \\
\hline Treated & 0.5543 & 31.5172 & - & - & - & - \\
\hline
\end{tabular}

Table 4.7 Results of de-nitrogenation of CTD (Continued)

\begin{tabular}{|c|c|c|c|c|c|c|}
\hline & \multicolumn{2}{|c|}{ Run 7 } & \multicolumn{2}{c|}{ Run 8 } & \multicolumn{2}{c|}{ Run 9 } \\
\hline Material & $\begin{array}{c}\text { Nitrogen } \\
\text { content } \\
(\text { wt \%) }\end{array}$ & $\begin{array}{c}\text { Nitrogen } \\
\text { Removed, } \\
(\%)\end{array}$ & $\begin{array}{c}\text { Nitrogen } \\
\text { content } \\
(\text { wt \%) }\end{array}$ & $\begin{array}{c}\text { Nitrogen } \\
\text { Removed, } \\
(\%)\end{array}$ & $\begin{array}{c}\text { Nitrogen } \\
\text { content } \\
(\text { wt \%) }\end{array}$ & $\begin{array}{c}\text { Nitrogen } \\
\text { Removed, } \\
(\%)\end{array}$ \\
\hline Feed & 0.9286 & - & 0.8942 & - & 0.9078 & - \\
\hline CTD+CS 2 & 0.9080 & - & 0.9124 & - & 0.8263 & - \\
\hline Treated & 0.5552 & 38.8546 & 0.5794 & 36.4972 & 0.5613 & 32.0707 \\
\hline Treated & 0.5427 & 40.2313 & 0.5744 & 37.0452 & 0.5677 & 31.2961 \\
\hline Treated & 0.5555 & 38.8216 & 0.6050 & 33.6914 & 0.4922 & 40.4333 \\
\hline Treated & 0.5861 & 35.4515 & 0.5681 & 37.7356 & 0.5415 & 34.4669 \\
\hline Treated & 0.6155 & 32.2137 & 0.6059 & 33.5927 & 0.5324 & 35.5682 \\
\hline Treated & 0.5775 & 36.3987 & 0.5246 & 42.5033 & 0.5239 & 36.5969 \\
\hline
\end{tabular}

1. Nitrogen removed $=\left(\% \mathrm{~N}\right.$ in $\mathrm{CTD}+\mathrm{CS}_{2}-\% \mathrm{~N}$ in $\left.\mathrm{CTD}+\mathrm{CS}_{2}+7\right) / \% \mathrm{~N}$ in $\mathrm{CTD}+\mathrm{CS}_{2} * 100$

2. Sample name "CTD $+\mathrm{CS}_{2}$ " means $10 \mathrm{~g}$ of Coal tar distillate diluted with $40 \mathrm{~g}$ of carbon disulfide

3. Sample name "treated" means $10 \mathrm{~g}$ of Coal tar distillate diluted with $40 \mathrm{~g}$ of carbon disulfide and treated with $7 \mathrm{~g}$ of air oxidized Nuchar SA20 for $2 \mathrm{hrs}$ in shaker bath at $30^{\circ} \mathrm{C}$.

The statistical results on treating CTD with air oxidized Nuchar activated carbon was given in Table 4.8. The average nitrogen content in the treated sample was $0.59 \mathrm{wt} \%$ and percent nitrogen removed was $33.4 \%$. 
Table 4.8 Statistical results on treating CTD with air oxidized Nuchar SA20

\begin{tabular}{|c|c|c|c|c|}
\hline & $\begin{array}{c}\text { N in Feed } \\
(\mathrm{wt} \%)\end{array}$ & $\begin{array}{c}\mathrm{N} \text { in control } \\
(\mathrm{wt} \%)\end{array}$ & $\begin{array}{c}\mathrm{N} \text { in treated } \\
(\mathrm{wt} \%)\end{array}$ & $\begin{array}{c}\text { N Removal } \\
(\%)\end{array}$ \\
\hline Average & 0.898 & 0.869 & 0.578 & 33.4 \\
\hline Standard Deviation & 0.068 & 0.086 & 0.053 & 4.4 \\
\hline No. of Samples & 9 & 8 & 57 & - \\
\hline
\end{tabular}

At GrafTech, the de-nitrogenated CTD sample was coked and graphitized to test the effect of reduced nitrogen compounds in the coal tar. The results of batch coking at GrafTech and the properties of the prepared graphite test specimen are given in Tables 4.9 and 4.10 respectively. Table 4.9 shows the yield of green coke obtained through pressure carbonization of the de-nitrogenated CTD was $42.2 \%$. The yield of calcined coke after heat treating the green coke to $1420^{\circ} \mathrm{C}$ was about $79 \%$. Attempts to measure the puffing character were unsuccessful because the test apparatus had mechanical failures that could not be repaired in time before the completion of this project.

Table 4.9 Product yield from batch cocking of de-nitrogenated Koppers CTD

\begin{tabular}{|c|c|}
\hline Weight of Koppers CTD, $\mathrm{g}$ & 378.1 \\
\hline Weight of green coke, $\mathrm{g}$ & 159.5 \\
\hline Yield of green coke, wt \% & 42.2 \\
\hline $\begin{array}{c}\text { Yield of calcined coke } \\
\text { (based on green coke wt), wt \% }\end{array}$ & 79 \\
\hline
\end{tabular}

. Table 4.10 shows the properties of three graphite test rods made from three different feedstocks.

1. De-nitrogenated Koppers CTD prepared at WVU- CTD Coke

2. A premium quality needle coke- Control

3. Decant oil- Petroleum based feedstock 
The CTE for the control is low compared to the other samples, since it was made from premium needle coke. The CTE of the treated CTD coke is significantly lower than that for the decant oil, confirming the coal-based feedstocks can make very good needle cokes for graphite products

Table 4.10 Properties of graphite test specimens

\begin{tabular}{|c|c|c|c|c|}
\hline Sample No. & Feedstock & $\begin{array}{c}\mathrm{CTE}, \\
\mathrm{ppm} /{ }^{\circ} \mathrm{C}\end{array}$ & $\begin{array}{c}\text { Bulk Density, } \\
\mathrm{g} / \mathrm{cm}^{3}\end{array}$ & $\begin{array}{c}\text { Resistivity, } \\
\mu \Omega-\mathrm{m}\end{array}$ \\
\hline 1 & CTD Coke & 0.209 & 1.494 & 9.80 \\
\hline 2 & Control & 0.107 & 1.472 & 9.04 \\
\hline 3 & Decant Oil & 0.250 & 1.460 & 8.88 \\
\hline
\end{tabular}




\section{CHAPTER 5: CONCLUSIONS/RECOMMENDATIONS}

This study aimed at determining the efficiency of activated carbon for the removal of nitrogen species from coal tar distillate and to examine the effect of amount of activated carbon, time and the effect of oxidation modification of activated carbon on the adsorption. Two kinds of activated carbons, Nuchar SA 20 and WVUAC 900-15 were used in this research work. Based on the results of the experimental work, the following conclusions can be drawn:

1. A standard experimental procedure was established for the denitrification of Koppers coal tar distillate (CTD).

2. The experimental work revealed that $\mathrm{CS}_{2}$ and THF were able to dissolve CTD more efficiently at 4:1 solvent to CTD weight ratio than toluene at 5:1 weight ratio.

3. Experiments were conducted following the established procedure using $5 \mathrm{~g}$ of Nuchar activated carbon and $\mathrm{CS}_{2}$ and THF as solvents. The results showed that $48.54 \%$ and $23.06 \%$ nitrogen was removed from CTD with $\mathrm{CS}_{2}$ and THF as solvents respectively. This suggests that Nuchar activated carbon was able to adsorb more nitrogen compounds from CTD with $\mathrm{CS}_{2}$ as a solvent than with THF as a solvent.

4. Percent nitrogen removed from the CTD increases with the increase in the amount of activated carbon added to the CTD solution, although there were some concerns about reproductivity. Results suggest that the CTD sample preparation is a critical factor in the experiment 
5. Activated carbon when added in a single step was able to remove more nitrogen species than a two-step adsorption process with an equivalent amount of carbon.

6. It was observed that $\%$ nitrogen in CTD decreases from 0.95 to 0.40 with in an hour and remains unchanged after one hour when $5 \mathrm{~g}$ of Nuchar activated carbon was added to solution of $\mathrm{CS}_{2}$ and CTD 4:1 wt ratio. This observation suggests that adsorption reaction between activated carbon and CTD is completed within an hour. After one hour, contact time has no effect on the adsorption process.

7. Oxidation modification of the surface improves the performance of both the activated carbons Nuchar SA 20 and WVUAC 900-15. Oxidation through nitric acid for 24 hrs is more effective than that with air.

8. A good relationship between the adsorption capacity and the surface $\mathrm{pH}$ value was observed. This suggests that the adsorption of the nitrogen compounds over activated carbons from the CTD may involve an interaction of the acidic surface functional groups on activated carbons with the nitrogen compounds.

9. It was observed that $5 \mathrm{~g}$ of unoxidized Nuchar SA 20 performed $67 \%$ better than the same amount of WVUAC 900-15 in removing nitrogen species from CTD.

Through this research work, it is observed that surface functional groups of the activated carbon play an important role in nitrogen removal. The nature of nitrogen groups present in CTD is another factor that effects adsorption process. Therefore, identification of surface functional groups of the activated carbon and nitrogen compounds in CTD using Temperature Programmed Desorption (TPD) and Gas Chromatography with a Nitrogen Phosphorus Detector (GC-NPD) respectively would be 
useful. More experiments need to be done to determine consistency of the results when analyzing the effect of increasing amounts of Nuchar SA20 on nitrogen levels in CTD. Since denitrification of CTD through adsorption utilizes large quantities of activated carbon, regeneration of the spent activated carbon is very important for cost effectiveness of the process.

In this work, an elemental analyzer is used to analyze percent nitrogen in treated CTD. However its lowest detection limit was close to the amounts of nitrogen contained in the CTD. Hence a much more sensitive method to analyze percent nitrogen is needed. 


\section{REFERENCES}

1. Dissertation "The Effect of Calcination Conditions on the Graphitizability of Novel Synthetic and Coal-Derived Cokes" by Barbara E. Bennett, 2000, WVU Morgantown, WV.

2. Thesis "Carbon Products from Coal Liquefaction Fractions" by Lizbeth LaureanoPerez, 2000, WVU Morgantown, WV.

3. A University, Industry, Government Cooperative Research Partnership. "Non-Fuel Use of Coal: Coal-Derived Carbon Materials". Nov. 12, 1993. The National Research Center for Coal and Energy ( NRCCE), West Virginia University, PO Box 6064, Morgantown, WV 26506-6064

4. Effects of oxidative modification of carbon surface on the adsorption of sulfur compounds in diesel fuel; Anning Zhou, Xiaoliang Ma, Chunshan Song; Applied Catalysis B: Environmental 87, Issues 3-4 (2009), pg 190-199

5. Needle Coke-a technological study; Singh, Himmat; Science and Technology Pg 67 (4), Vol. 44, No.N2, and ISSN: 0014-0058

6. Needle Coke from Nitrogen Removed and Coal-Derived Feedstocks, Final Report: Peter Stansberry, John Chang, GrafTech International Holdings Inc.

7. http://www.wipo.int/pctdb/en/wo.jsp?IA=US1980000135\&DISPLAY=DESC

8. http://www.graftech.com/PRODUCTS/Graphite-Electrodes/Making-aUCAR\%C2\%AE-Electrode.aspx

9. John W. Newman "What is Petroleum Pitch?" in Petroleum Derived Carbons, Marvin L. Deviney and Thomas M. O'Grady eds., ACS Symposium Series 21, Washington, D. C, 1976.

10. Adams "Delayed Coking: Practice and Theory," In Introduction to Carbon Technologies, H. Marsh, Edward A. Heintz, and Francisco RodriguezReinoso eds., University of Alicante, 329-423.

11. Ellis, Paul J. and Paul, Christopher A., "Tutorial: Petroleum Coke Calcining and Uses of Calcined Petroleum Coke," $3^{\text {rd }}$ International Conference on Refining Processes, AIChE 2000 Spring National Meeting, March 5-9, 2000, Atlanta, GA

12. Gary, James H. and Handwerk, Glenn E. Petroleum Refining: Technology and Economics. New York: M. Dekker. 1975. 
13. Developing Coal Tar/Petroleum Pitches- A Presentation by Melvin D. Kiser (Marathon Ashland Petroleum Company), Robert H. Wombles (Koppers Industries, Inc) www.koppers.com/docs/White_Papers/KOPHTC_TMS00_DEV_PETROL.ppt

14. Fredersdorff, C.G., "Reactions of Carbon with Carbon Dioxide and with Steam", Institute of Gas Technology Res. Bulletin, No. 19, 1955.

15. Balci, S., Dogu G. and Dogu T., "Structural Variations and a Deactivation Model for Gasification of Coal", Ind. Eng. Chem. Res., pp.1454-58, 1987.

16. Hampartsoumian, E. and Murdoch, P.L., "Reactivity of Coal Chars Gasified in a Carbon Dioxide Environment" Comb. Sci. and Tech, 1993.

17. Hsisheng, Teng and Lin, Hung-chi, "Activated Carbon Production from Low Ash Sub bituminous Coal with CO2 Activation”, AIChE Journal, pp. 1170-76, 1998.

18. Ljubisa R. Radovic, Teresa J. Bandosz et al. "Chemistry and Physics of Carbon", Volume 28, Chapter 2, Page 118 Library of Congress, 2003.

19. Smisek, M. and Cerny, S., "Active Carbon", American Elsevier Publishing Co. NY, 1964.

20. Hassler, J.W., “Active Carbon”, Chemical Publishing Co. NY, 1974.

21. Merchant, Akbar A. and Petrich, Mark A., "Preparation and Characterization of Activated Carbons from Scrap tires, Almond shells and Illinois coal", Chem. Eng. Comm. 1992.

22. Development of surface area and pore structure for activation of anthracite coal; John W. Zondlo, Michael R. Velez; Fuel Processing Technology 88 (2007) 369-374

23. Harry Marsh, Francisco Rodríguez-Reinoso “Activated carbon” Elsevier Science \& Technology, 2006.

24. Surface modification and characterization of a coal-based activated carbon; B. Saha, P. Chingombe, R.J. Wakeman; Carbon 43 (2005) 3132-3143

25. Importance of activated carbon's oxygen surface functional groups on elemental mercury adsorption; Y.H.Li, C.W. Lee, B.K.Gullet; Fuel 82 (2003) 451-457

26. Sulfur dioxide adsorption by activated carbons having different textural and chemical properties; Nilgun Karatepe, _Ilkun Orbak, Reha Yavuz, Ays_e Ozyug uran; Fuel 87 (2008) 3207-3215 
27. Article on "Hydrocarbon Evaporative Emissions \& Control for Automotives Adsorption \& Activated Carbon" by Neville Bugli, American Filtration and Separations Society.

28. Role of surface oxygen-containing functional groups in liquid phase adsorption of nitrogen compounds on carbon-based adsorbents, Energy \& Fuels 23 (2009) 3940

29. www.pss.aus.net

(http://www.pss.aus.net/products/micromeritics/equip_surface_area/2010/2020.html)

30. James B. Condon "Surface area and porosity determinations by physisorption measurements and theory", Elsevier 2006. 